\title{
Primary Traumatic Axonopathy in Mice Subjected to Impact Acceleration: A Reappraisal of Pathology and Mechanisms with High-Resolution Anatomical Methods
}

\author{
Nikolaos K. Ziogas ${ }^{1}$ and Vassilis E. Koliatsos ${ }^{1,2,3}$ \\ ${ }^{1}$ Division of Neuropathology, Department of Pathology, The Johns Hopkins University School of Medicine, Baltimore, Maryland 21205, 2Department of \\ Neurology, The Johns Hopkins University School of Medicine, Baltimore, Maryland 21205, and '3epartment of Psychiatry and Behavioral Sciences, The \\ Johns Hopkins University School of Medicine, Baltimore, MD 21205
}

Traumatic axonal injury (TAI) is a common neuropathology in traumatic brain injury and is featured by primary injury to axons. Here, we generated TAI with impact acceleration of the head in male Thy1-eYFP- $H$ transgenic mice in which specific populations of neurons and their axons are labeled with yellow fluorescent protein. This model results in axonal lesions in multiple axonal tracts along with bloodbrain barrier disruption and neuroinflammation. The corticospinal tract, a prototypical long tract, is severely affected and is the focus of this study. Using optimized CLARITY at single-axon resolution, we visualized the entire corticospinal tract volume from the pons to the cervical spinal cord in 3D and counted the total number of axonal lesions and their progression over time. Our results divulged the presence of progressive traumatic axonopathy that was maximal at the pyramidal decussation. The perikarya of injured corticospinal neurons atrophied, but there was no evidence of neuronal cell death. We also used CLARITY at single-axon resolution to explore the role of the NMNAT2-SARM1 axonal self-destruction pathway in traumatic axonopathy. When we interfered with this pathway by genetically ablating SARM1 or by pharmacological strategies designed to increase levels of Nicotinamide (Nam), a feedback inhibitor of SARM1, we found a significant reduction in the number of axonal lesions early after injury. Our findings show that high-resolution neuroanatomical strategies reveal important features of TAI with biological implications, especially the progressive axonopathic nature of TAI and the role of the NMNAT2-SARM1 pathway in the early stages of axonopathy.

Key words: axonopathy; NMNAT2-SARM1; CLARITY; corticospinal tract; traumatic brain injury; 2-photon microscopy

Significance Statement

In the first systematic application of novel high-resolution neuroanatomical tools in neuropathology, we combined CLARITY with 2-photon microscopy, optimized for detection of single axonal lesions, to reconstruct the injured mouse brainstem in a model of traumatic axonal injury (TAI) that is a common pathology associated with traumatic brain injury. The 3D reconstruction of the corticospinal tract at single-axon resolution allowed for a more advanced level of qualitative and quantitative understanding of TAI. Using this model, we showed that TAI is an axonopathy with a prominent role of the NMNAT2-SARM1 molecular pathway, that is also implicated in peripheral neuropathy. Our results indicate that high-resolution anatomical models of TAI afford a level of detail and sensitivity that is ideal for testing novel molecular and biomechanical hypotheses.

\section{Introduction}

Traumatic brain injury (TBI) is associated with mixed neuropathologies, including contusions, diffuse or traumatic axonal in-

Received Aug. 18, 2017; revised Feb. 21, 2018; accepted March 15, 2018.

Author contributions:V.E.K. and N.K.Z. designed research; N.K.Z. and V.E.K. performed research; N.K.Z. and V.E.K. analyzed data; V.E.K. and N.K.Z. wrote the paper.

This work was supported by Department of Defense W81XWH-14-0396, State of Maryland TEDC0 2015-MSCRFI1718, National Institutes of Health R01EY028039, the Sidran Family Foundation, and the Spyros N. Lemos Memorial Fund. N.K.Z. was supported by the Johns Hopkins-LIBRA fellowship program. We thank J. Boyd for advice and invaluable assistance with 2-photon microscopy; J. Ryu and W. Gilliam for breeding of Thy1-eYFP-H/SARM1 ${ }^{-1-}$ mice; T. Omer for assistance with axon counts; K.T. Ramesh and F. Madouh for technical assistance with the impact jury (TAI), meningeal or parenchymal hemorrhage, and protein aggregation. TAI is the commonest pathology regardless of TBI

acceleration device; A. Hoke for supplying SARM1 ${ }^{-1-}$ founders; A. Popratiloff and C. Brantner of the Nanofabrication and Imaging Center of George Washington University for help with 2-photon imaging resources; and all members of the V.E.K. laboratory for feedback and support.

The authors declare no competing financial interests.

Correspondence should be addressed to either Dr. Vassilis E. Koliatsos or Dr. Nikolaos K. Ziogas, Johns Hopkins University School of Medicine, 720 Rutland Avenue, Ross Research Building, Room 558, Baltimore, MD 21205, E-mail: koliat@jhmi.edu or nziogas1@jhmi.edu.

DOl:10.1523/JNEUROSCI.2343-17.2018

Copyright $\odot 2018$ the authors $\quad 0270-6474 / 18 / 384031-17 \$ 15.00 / 0$ 
cause or severity and is thought to be the result of dynamic loading of axons during rotational acceleration of the head (Maxwell et al., 1993; Smith et al., 1997, 2003). This mechanism causes immediate axonal disruption leading to secondary axonal or perikaryal degeneration. One of the distinguishing features of TAI is that injury begins at the axon, as contrasted to axonal damage or degeneration that is secondary to perikaryal injury or cell death (Waller, 1850; Finn et al., 2000; Sasaki et al., 2009; Osterloh et al., 2012).

Animal models of TBI are featured by various degrees of axonal injury, but only in few cases there is a clear distinction of primary axonal injury from secondary Wallerian degeneration (Xiong et al., 2013). Part of the problem is that most popular models of TBI either are solely based on focal lesions or have substantial focal components that directly cause neuronal cell death. In rodents, one of the best-characterized models of diffuse TBI with primary axonal injury is impact acceleration (IA) (Marmarou et al., 1994). Using a modification of this model for the mouse cranium, we have already shown primary traumatic axonopathy in multiple CNS pathways, including the visual system, corticospinal tract (CST), corpus callosum, medial and lateral lemniscus, and the cerebellar white matter (Xu et al., 2016).

Another challenge in modeling TAI is that available methods to demonstrate axonal injury are primarily based on axonal transport blockade markers, such as APP, that label damaged axons temporarily (Stone et al., 2000) or silver degeneration stains that may label only degenerating axons (Blackstad et al., 1981). In addition, the near-absence of the third dimension in routine histological sections allows only a limited sampling of tissue and leads to underestimation of the extent of axonal abnormalities. The advent of transgenic mice that express the yellow fluorescent protein (YFP) under Thyl promoter offers great promise for a sensitive and specific labeling of axonal pathology (Greer et al., 2011, 2013; Hånell et al., 2015). More importantly, the invention of methods that render the brain tissue transparent, such as CLARITY (Chung et al., 2013; Tomer et al., 2014), makes it possible, for the first time, to microscopically study whole axon tracts and visualize, analyze, and quantitate the full 3D extent of axonal pathology.

The present study represents the first application of CLARITY in TBI research. Here, we subject Thy1-eYFP-H transgenic mice to IA to generate multifocal TAI accompanied by blood-brain barrier $(\mathrm{BBB})$ disruption and neuroinflammatory responses by resident microglia or blood-borne macrophages. We then focus on axonal pathology in the CST, a prototypical long-axon pathway, which we characterize with CLARITY and 2-photon microscopy at single-axon resolution. Based on CLARITY preparations, we show the $3 \mathrm{D}$ distribution, precise magnitude, and the identity of TAI as progressive axonopathy. We also explore the role of a recently proposed molecular pathway of axonal self-destruction in the early stages of traumatic axonopathy. This pathway is triggered when the axonal maintenance factor nicotinamide nucleotide adenylyltransferase 2 (NMNAT2) fails to reach the distal axon after injury, thus initiating a sterile alpha and TIR motif containing 1 (SARM1)-dependent axonal degeneration program in which $\mathrm{NAD}^{+}$metabolism plays a central role (Gilley et al., 2010; Osterloh et al., 2012; Gerdts et al., 2015, 2016; Hill et al., 2016). To explore the significance of the NMNAT2-SARM1 pathway in traumatic axonopathy, we interfered with SARM1 signaling by knocking out SARM1 or by pharmacological strategies designed to increase levels of the SARM1 inhibitor nicotinamide (Nam) after blocking its consumption by Nicotinamide phosphoribosyltransferase (NAMPT) with a small-molecule
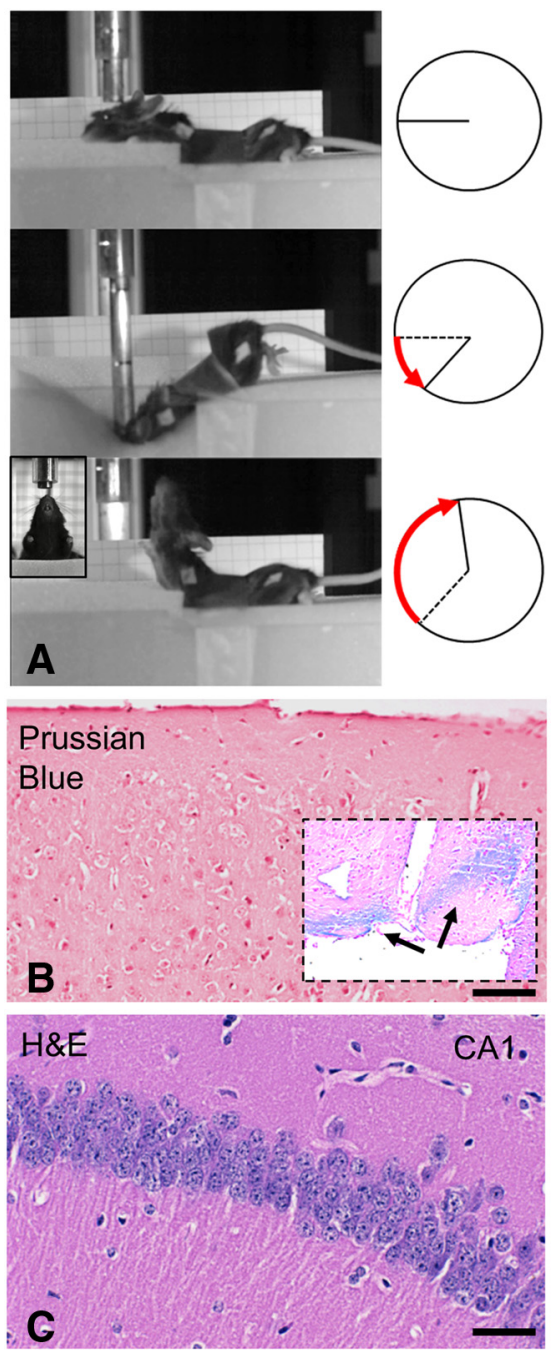

Figure 1. Main features of the IA model. $\boldsymbol{A}$, These stills from a high-speed video camera monitoring (20,000 frames per second) of an IA session depict two key events in the IA sequence, including a push-down phase with both translational and rotational acceleration, and then an upward whiplash phase primarily involving rotational acceleration of the head. Main rotational events are depicted with geometrical shapes on the right (red arrows), next to the corresponding halftones. $\boldsymbol{B}$, Prussian blue staining at $7 \mathrm{~d}$ after injury shows the lack of hemosiderin signal in mouse cortex under the disc (impact site), a finding consistent with absence of contusion. Inset, Positive diffuse low signal around the mesencephalic flexure of the brainstem, site that may correspond to the concentration of acceleration or other injurious events. Scale bar, $100 \mu \mathrm{m}$. C, This H\&E-stained section through the CA1 sector of hippocampus at $7 \mathrm{~d}$ after injury shows lack of eosinophilia in pyramidal neurons, suggestive of absence of anoxicischemic injury. Scale bar, $30 \mu \mathrm{m}$.

inhibitor, FK866 (Essuman et al., 2017). Our findings suggest that high-resolution anatomical strategies advance research on TAI by precisely localizing the injury, determining nature and severity, and allowing work into the molecular mechanisms of TAI-associated axonopathy.

\section{Materials and Methods}

Experimental animals. Our experimental subjects were 5-week-old male C57BL/6 mice (strain code: 027, Charles River Laboratories, RRID: IMSR_CRL:27), 5-week-old male Thy1-eYFP-H transgenic mice (catalog \#003782, The Jackson Laboratory, RRID:IMSR_JAX:003782), and 5-week-old male Thy1-eYFP-H/SARM1 ${ }^{-1-}$ transgenic mice. The transgenic line Thy1-eYFP-H expresses Thy1-driven YFP in specific populations of CNS and PNS neurons, including pyramidal neurons in layer $\mathrm{V}$ of motor and sensory neocortex, with superb delineation of the CST 

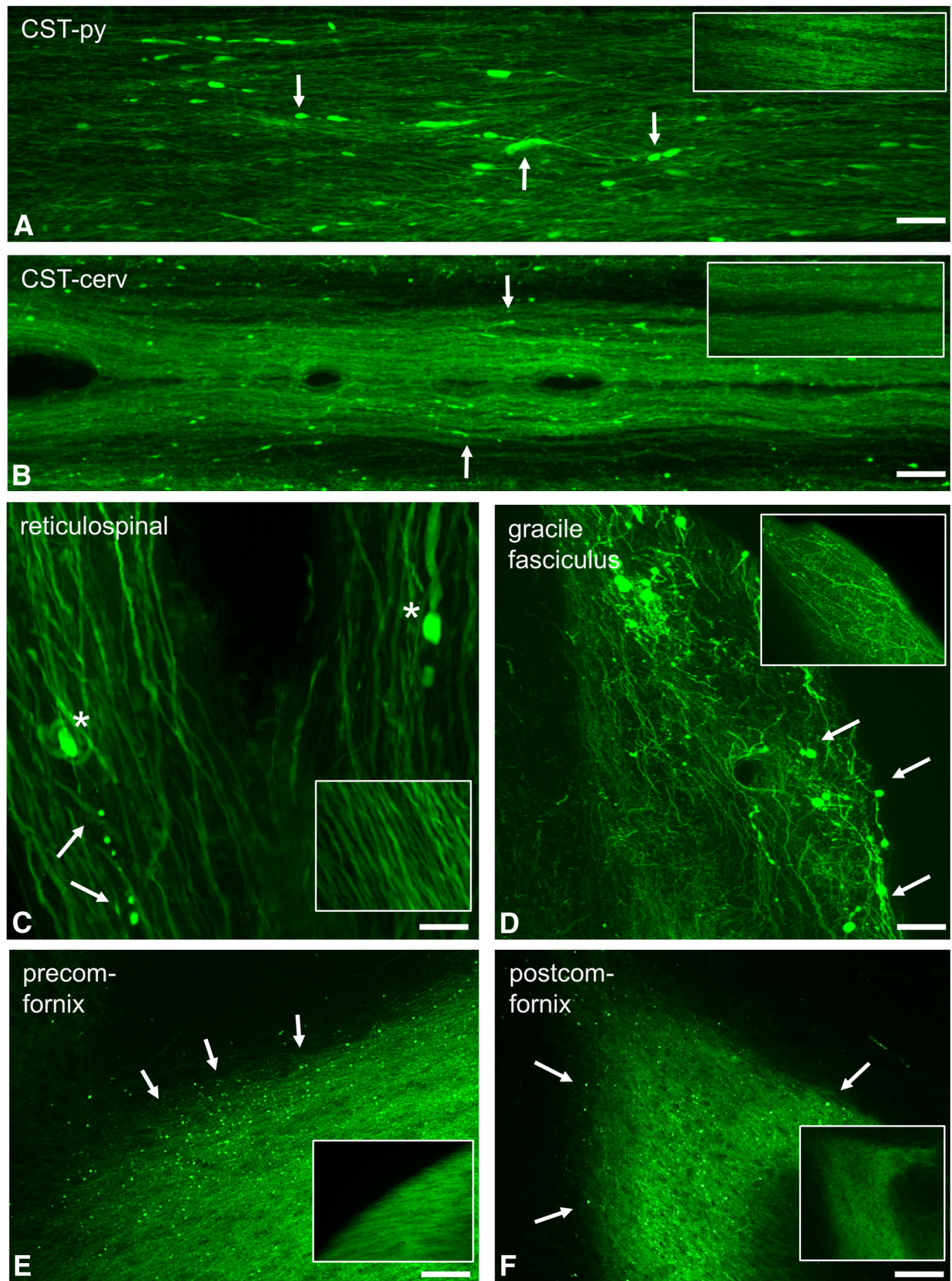

Figure 2. Multifocal traumatic axonopathy resulting from IA of the head in YFP-H transgenic mice. Only representative fiber tracts are shown. $\boldsymbol{A}, \boldsymbol{B}$, A sagittal section through the pyramids $(\boldsymbol{A})$ and a transverse section through the dorsal cervical cord $(\boldsymbol{B})$ show characteristic undulations, swellings, and bulbs consistent with traumatic damage to axons (arrows). Scale bars: $\boldsymbol{A}, 30 \mu \mathrm{m} ; \boldsymbol{B}, 50 \mu \mathrm{m}$. C, ${ }^{*}$ Bulbs in the large diameter axons of the RST. Bottom left, A classical Wallerian degeneration profile (arrows). Scale bar, $20 \mu \mathrm{m}$. D, Numerous large swellings near the termination of the gracile fasciculus in the gracile nucleus. Scale bar, $50 \mu \mathrm{m} . \boldsymbol{E}, \boldsymbol{F}$, Small swellings, only seen in injured subjects, are distributed along the precommissural fornix ( $\boldsymbol{E}$, arrows) and near the termination of postcommissural fornix at the mammillary bodies ( $\boldsymbol{F}$, arrows). Scale bar, $50 \mu \mathrm{m}$. Insets, Images from sham controls for each axonal pathway.

throughout its entire course from cortex to spinal cord (Porrero et al., 2010). The expression of YFP was ascertained by genotyping for the $\mathrm{Tg}($ Thy1-YFP)HJrs allele. All animals received humane care in compliance with the Guide for the care and use of laboratory animals (National Academy Press, 2011) and based on procedures approved by the Animal Care and Use Committee of the Johns Hopkins Medical Institutions. Animals were housed in a vivarium with $12 \mathrm{~h}$ light/ $12 \mathrm{~h}$ dark cycles and given access to pellet food and water ad libitum.
IA model of TBI. IA injury was produced under gas anesthesia with $2 \%$ isoflurane. Under aseptic conditions and with the subject in a smallanimal stereotactic frame (David Kopf Instruments), a 5-mm-diameter steel disc was glued on the exposed cranium between bregma and lambda to prevent skull fracture. The mouse was then placed prone on a foam bed under a hollow Plexiglas tube and secured with tape as described previously (Xu et al., 2016). Injury was produced by dropping a brass weight from a height of $1 \mathrm{~m}$ through the Plexiglas tube onto the disk. 
In all cases except the impact dose-response study outlined below, that weight was $60 \mathrm{~g}$. The foam bed was pulled immediately at the rebound of the weight off the metal disc, such as to prevent a second impact. The metal disc was then removed, scalp incision was closed with surgical staples, and the animal returned to cage for full recovery. Subjects with skull fractures confirmed with a surgical microscope were excluded from the study. Sham-operated animals were subject to the same procedures without the weight drop component. For a video recording of the IA injury, a high-frame rate camera, Fastcam SA5 (Photron) was used, shooting at 20,000 frames per second for the entire duration of the injury.

General neuropathology and study of axonal injury with fluorescence or confocal microscopy. At the appropriate time points, C57BL/6 or Thyl-eYFP-H mice were transcardially perfused with freshly depolymerized PFA ( $4 \%$ in $0.1 \mathrm{~m}$ PBS, pH 7.4). Brains were postfixed in the same fixative for various periods of time. For general neuropathological characterization of the injury, we used brain tissues from C57BL/6 animals perfused $7 \mathrm{~d}$ after injury that had been postfixed for $3 \mathrm{~d}$ in PFA. Tissues were embedded in paraffin and coronal sections $(10 \mu \mathrm{m})$ were stained for cresyl violet, Prussian blue, and $\mathrm{H} \& \mathrm{E}$.

For characterization of the axonal injury, we used brain tissues from Thyl-eYFP-H mice perfused 3, 24, and $48 \mathrm{~h}$ after injury. These tissues were postfixed overnight $\left(4^{\circ} \mathrm{C}\right)$ in PFA, then saturated with $20 \%$ glycerol containing $5 \%$ DMSO, frozen in dry ice, and sectioned at the sagittal or coronal plane $(40 \mu \mathrm{m})$. Sagittal brain sections from injured and control Thy1eYFP- $H$ mice ( $n=10$ per group) were used to characterize injured YFP-labeled tracts based on the presence of axonal swellings. Sections were studied with epifluorescence or confocal microscopy. For confocal microscopy, sections between the midsagittal plane and a plane $0.5 \mathrm{~mm}$ lateral to midline that contain the entire CST were imaged with a LSM700 unit at $40 \times$. In some cases, imaging was done with care not to saturate the fluorescent signal at the axonal swelling sites and the ImageJ edge detection function was applied after acquisition to visualize cytosolic vesicles and organelles.

Blood-brain barrier (BBB) study. Brain endothelial cells from injured and control C57BL/ 6 mice ( $n=5$ per group) were labeled by transcardial injection of $150 \mu \mathrm{l}$ of Lycopersicon Escelentum lectin (LEA) conjugated with DyLight 488 (Vector Laboratories catalog \#DL-1174, RRID: AB_2336404) 3 min before perfusion with 4\% PFA. Sagittal sections were blocked with $5 \%$ donkey serum in PBS with $0.2 \%$ Triton X-100 (PBST) for $3 \mathrm{~h}$ and then incubated in donkey anti-mouse IgG conjugated with Cy3 (Jackson ImmunoResearch Laboratories catalog \#715165150, RRID: AB_2340813) in blocking solution for $2 \mathrm{~h}$. After washing, sections were counterstained with DAPI and imaged using an Axioplan microscope (Carl Zeiss) or a LSM-700 confocal microscope.

Impact dose-response study. Thy1-eYFP-H mice injured with sham procedures or 20,40 , and $60 \mathrm{~g}$ IA ( $n=5$ per group) were perfused with $4 \%$ PFA $24 \mathrm{~h}$ after injury, and brainstems were sectioned coronally on a sliding microtome. Four sections per subject through the pyramids were mounted on a microscopic slide and imaged with an LSM-700 confocal microscope. Axonal swellings were counted by blinded investigators using ImageJ.

CLARITY-based brain clearing optimized for axonal injury detection, immunohistochemistry, imaging, and quantification. For brain clearing, we used a modified CLARITY method (Chung et al., 2013). In summary, injured and control Thy1-eYFP-H mice were transcardially perfused with $4 \%$ PFA at 3 and $24 \mathrm{~h}$ after injury ( $n=3$ per group). Brains were incubated in a hydrogel solution containing 4\% PFA, 2\% acrylamide (BioRad catalog \#1610140), $0.025 \%$ bis-acrylamide (Bio-Rad catalog \#1610142), and 0.25\% VA-044 initiator (Wako catalog\#VA-044) in $0.1 \mathrm{M}$ PBS for $3 \mathrm{~d}$ in $4^{\circ} \mathrm{C}$. Tissues were then degassed in a vacuum desiccator and polymerized at $37^{\circ} \mathrm{C}$ for $3 \mathrm{~h}$. After removal of the excess gel, brains were transferred in $50 \mathrm{ml}$ of a clearing solution consisting of $4 \%$ SDS in 200 mu boric acid, $\mathrm{pH} 8.5$, for 2 weeks at $37^{\circ} \mathrm{C}$ until fully transparent. After clearing, brains were incubated in PBST for $2 \mathrm{~d}$. CLARITY-based immunohistochemistry (IHC) for amyloid precursor protein ( $\beta$-APP or APP) used a polyclonal antibody against the $\mathrm{C}$ terminus of the protein that is widely used as a marker of axonal injury (1:60; Thermo Fisher Scientific catalog \#51-2700, RRID:AB_2533902): after the clearing step, brains were incubated for $5 \mathrm{~d}$ in APP/PBST $\left(37^{\circ} \mathrm{C}\right)$ followed by a $2 \mathrm{~d}$ PBST wash and then incubation in anti-rabbit IgG AlexaFluor-568 (1:60; Thermo Fisher Scientific catalog \#A-11011, AB_143157) in PBST for $5 \mathrm{~d}$ at $37^{\circ} \mathrm{C}$. After a final wash, brains were transferred to FocusClear (CelExplorer catalog \#FC-101) and mounted for imaging.

To achieve single-axon resolution to detect individual axonal lesions, we optimized two-photon microscopy using HyD detectors in the nondescanned position and CLARITY-optimized, long-working-distance, high-numerical-aperture $25 \times$ objectives. This key modification of the original CLARITY protocol was achieved with a TCS SP8 MP multiphoton microscope coupled with HyD NDD detectors (Leica Microsystems) and a motorized $6 \mathrm{~mm}$ working-distance, CLARITY-optimized objective (Leica Microsystems). For each case, we cleared the whole mouse brain 

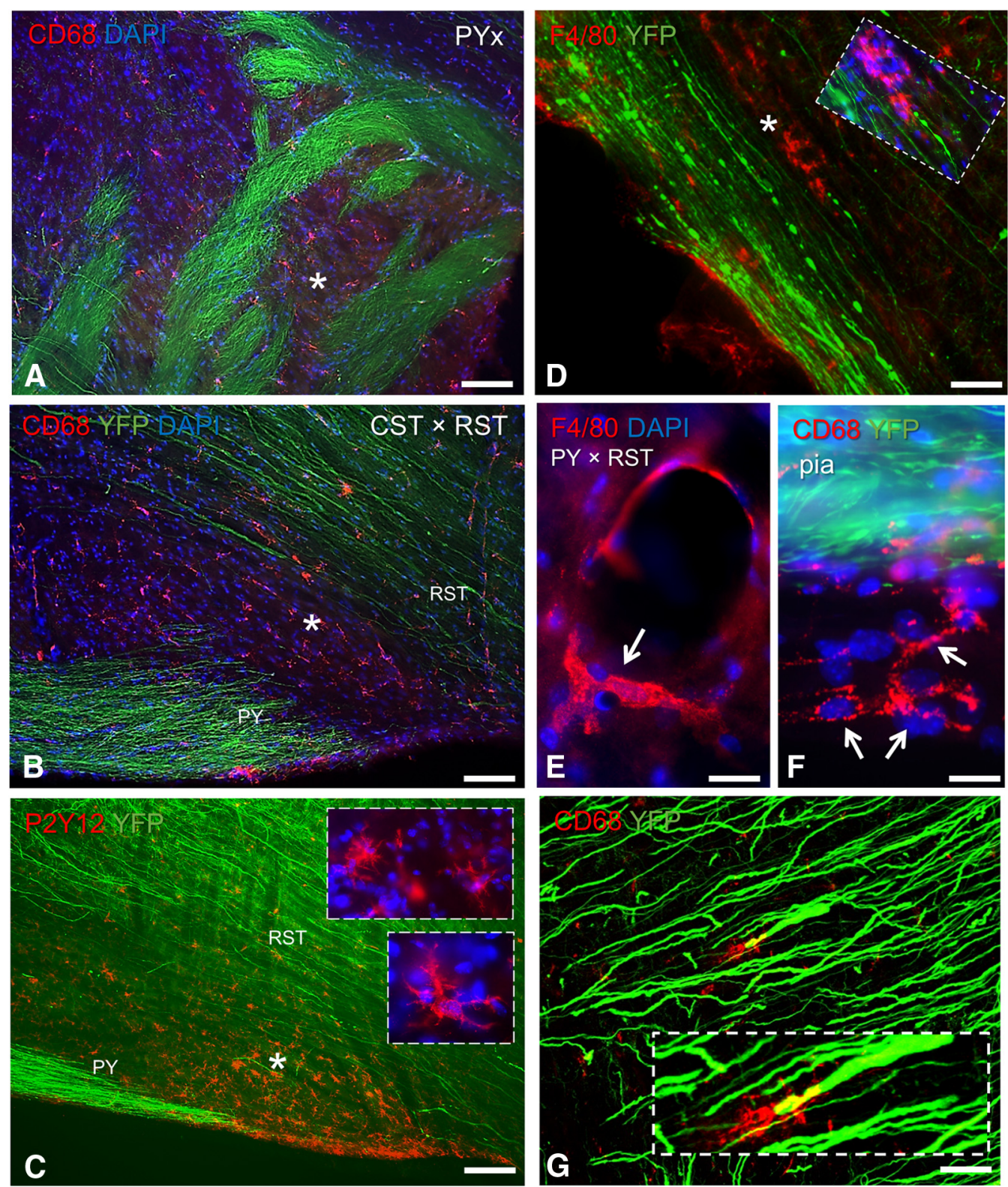

Figure 4. Neuroinflammatory responses in YFP mice after IA. $\boldsymbol{A}-\boldsymbol{C}$, Resident microglial activation in select portions of the CST, including decussation of the pyramids $(\boldsymbol{A})$ and the crossing of the lower pyramids with the RST $(\boldsymbol{B}, \boldsymbol{C})$ at $48 \mathrm{~h}$ after injury. ${ }^{*}$ Main areas of activation. $\boldsymbol{A}, \boldsymbol{B}$, Sections immunolabeled with antibodies against $\mathrm{CD} 68$. $\boldsymbol{C}$, Section immunostained with an antibody against P2Y12. C, Insets, Representative transformed P2Y12 (+) profiles from the same region. Top, Inset, Two clusters of such cells. Bottom inset, Two characteristic macrophages with stout, thorny processes. Scale bars: $\boldsymbol{A}, \boldsymbol{B}, 50 \mu \mathrm{m} ; \boldsymbol{C}, 70 \mu \mathrm{m} . \boldsymbol{D}-\boldsymbol{F}$, Blood-borne parenchymal $(\boldsymbol{D}, \boldsymbol{E})$ and pial $(\boldsymbol{F})$ inflammatory responses at $48 \mathrm{~h}$ after injury. $\boldsymbol{D}, \boldsymbol{E}$, Sections immunostained with the peripheral macrophage marker F4/80. $\boldsymbol{F}$, Section immunolabeled with antibody CD68. D, F, YFP-labeled injured axons. All images are from the lower pyramids. $\boldsymbol{D}, \boldsymbol{E}$, Pericapillary "rings" of blood-borne macrophages; these are indicated with an asterisk in $\boldsymbol{D}$ and further magnified in inset (inset counterstained with DAPI to show the presence of a capillary). $\boldsymbol{E}$, Arrows indicate macrophages. $\boldsymbol{F}$, Arrows indicate pial CD68 (+) macrophages. Scale bars: $\boldsymbol{D}, 30 \mu \mathrm{m} ; \boldsymbol{E}, \boldsymbol{F}, 5 \mu \mathrm{m} . \boldsymbol{G}$, In this CD68-immunolabeled section, there is a cluster of transformed CD68 (+) microglial cells surrounding the end bulb of an injured axon. Such profiles can be occasionally observed $48 \mathrm{~h}$ after IA. Scale bar, $60 \mu \mathrm{m}$.

and imaged the brainstem for further analysis. The imaging of each mouse brainstem took $24 \mathrm{~h}$ and generated $\sim 120 \mathrm{~GB}$ of data per animal.

For $3 \mathrm{D}$ visualization and quantitative analysis of axonal injury of cleared brainstems, we used the software suite Imaris (Bitplane). The spot detection analysis was based on the size of axonal lesions in the $3 \mathrm{D}$ space. Because of the size of imaging data, we used a 128 GB-RAM workstation. For the detection and quantification of axonal swellings based on YFP and APP, we used the spot detection function for the whole CST volume from the pons to the pyramidal decussation or cervical spinal cord.

Genetic deletion of SARM1. Sarm $1^{-1-}$ mice (Szretter et al., 2009) (RRID:MGI:5507810) were obtained from Dr. Ahmet Hoke at Johns Hopkins and cross-bred in house with Thy1-eYFP-H mice; SARM1 deletion was confirmed by PCR. Thy1-eYFP-H/SARM1 ${ }^{-1-}$ and Thy1-
eYFP-H/SARM1 ${ }^{+/+}$mice were injured with $60 \mathrm{~g} \times 1 \mathrm{~m}$ IA $(n=3$ per group). Experimental sample sizes were predetermined based on power analysis from previous CLARITY experiments (see Fig. 10). All experimental subjects have been included in the study. Counts were performed by a blinded investigator. Subjects were killed $24 \mathrm{~h}$ after injury and brain/spinal cord tissues were processed with CLARITY as in previous section.

Pharmacological interference with the NMNAT2-SARM1 pathway. Thyl-eYFP-H mice were injured with $60 \mathrm{~g} \times 1 \mathrm{~m} \mathrm{IA}(n=3$ per group), and treated with FK866 (10 mg/kg i.p.) (Sigma-Aldrich catalog \#F8557) or vehicle starting immediately after injury and then continuing every $6 \mathrm{~h}$ until $24 \mathrm{~h}$ after injury, when the experiment was terminated (Busso et al., 2008, Bruzzone et al., 2009, Nahimana et al., 2009; Van Gool et al., 2009). 
Experimental sample sizes were determined with power analysis from previous CLARITY experiments, as in the previous section. All experimental subjects were included in the study. Counts were performed by a blinded investigator. Mice were killed $24 \mathrm{~h}$ after injury and tissues were processed with CLARITY.

Electron microscopy. Injured and control Thy1-eYFP- $H$ mice ( $n=3$ per group) were transcardially perfused with $4 \% \mathrm{PFA} / 2 \%$ glutaraldehyde $24 \mathrm{~h}$ after injury. Brains were postfixed overnight in the same solution $\left(4^{\circ} \mathrm{C}\right)$. Tissue cubes through the lower pyramids were further fixed in PFA/glutaraldehyde solution for $5 \mathrm{~d}\left(4^{\circ} \mathrm{C}\right)$, treated with $2 \%$ osmium tetroxide in $0.1 \mathrm{~m}$ sodium cacodylate, $\mathrm{pH}$ 7.4, and then stained en bloc with $2 \%$ uranyl acetate. Blocks were then dehydrated, embedded in Embed 812 (Electron Microscopy Sciences), and sectioned on a Reichert Jung Ultracut E microtome. Semithin sections were stained with $1 \%$ toluidine blue. Thin sections were stained with uranyl acetate followed by lead citrate and photographed on a Carl Zeiss Libra 120 electron microscope equipped with a Veleta (Olympus) camera.

Retrograde tracing of corticospinal pyramidal neurons to identify injured cell bodies. Recombinant cholera toxin (subunit B) conjugated to AlexaFluor-594 (Thermo Fisher Scientific catalog \#C22842) was injected stereotactically into the CST at the level of the ventral pons (4.1 $\mathrm{mm}$ caudal to bregma, 0.7 lateral to midline, $5.25 \mathrm{~mm}$ ventral to pial surface) of C57BL/6 mice (Paxinos and Franklin, 2012). Tracer (0.5 $\mu \mathrm{l}$ of a $1.0 \mathrm{mg} / \mathrm{ml}$ solution in PBS) was pressure injected with glass micropipettes as described previously (Capurso et al., 1997; Clatterbuck et al., 1998). Two weeks later, mice were subjected to IA or sham injury and 3, 7, and $14 \mathrm{~d}$ after injury mice were perfused with $4 \%$ PFA ( $n=5$ per injury or sham $\times$ survival time). To colocalize p-c-Jun and CTB immunoreactivities, we performed chromogen-based, duallabel IHC or fluorescent IHC for p-c-Jun only. In the former case, we used immunoperoxidase-DAB for CTB and alkaline-phosphatase for p-c-Jun. Briefly, sections were blocked in $5 \%$ normal donkey serum and $0.2 \%$ Triton $\mathrm{X}-100$ ( $2 \mathrm{~h}$, room temperature $)$ and then incubated in primary antibodies against CTB (1:1000; List Laboratories catalog \#703) and p-c-Jun (Ser 63) (1:100; Cell Signaling Technology catalog \#9261, RRID: $\mathrm{AB} \_2130159$ ) (overnight, $4^{\circ} \mathrm{C}$ ). For immunoperoxidase labeling, after incubation in biotinylated donkey anti-goat IgG antibody (1:200; Jackson ImmunoResearch Laboratories catalog \#705065147) and then in avidin-biotin HRP (Vectastain Elite ABC Kit; Vector Laboratories catalog \#PK-6100), sections were developed with a standard DAB reaction. For alkaline-phosphatase staining, sections were incubated in ImmPress-AP anti-rabbit IgG polymer detection kit (Vector Laboratories catalog \#MP5401) and developed with a blue alkaline-phosphatase substrate (Vector Laboratories catalog \#SK5300). In the case of p-c-Jun immunofluorescence, after blocking in 5\% normal donkey serum and $0.2 \%$ Triton X-100 ( $2 \mathrm{~h}$, room temperature), sections were incubated in the p-c-Jun antibody $(1: 100)$ overnight at $4^{\circ} \mathrm{C}$. After washing and incubation in a secondary Cy2 conjugated donkey anti-rabbit IgG (1:200; Jackson ImmunoResearch Laboratories catalog \#711225152) for $2 \mathrm{~h}$ in room temperature, sections were counterstained in DAPI and coverslipped in DPX. Fluorescent sections were imaged with an Axioplan microscope (Carl Zeiss) and a LSM-700 confocal microscope (Carl Zeiss).
Phosphorylated-c-Jun (+) layer V neurons were counted on 6 serial sections. Volumes of layer $\mathrm{V}$ pyramidal neurons were stereologically estimated with the nucleator probe by blinded investigators using StereoInvestigator software (MBF Bioscience).

TUNEL. Control and injured C57BL/6 mice were perfused at 3, 7, 14, and $30 \mathrm{~d}$ ( $n=3$ per group) with $4 \%$ PFA. Brains were sectioned at the sagittal plane $(40 \mu \mathrm{m})$. For TUNEL staining of dying neurons, we used TMR red (Sigma-Aldrich catalog \#12156792910) as per the manufacturer's instructions. Sections incubated with DNase I (Sigma-Aldrich cata$\log$ \#AMPD11KT) served as positive controls. After TUNEL reactions, sections were coverslipped in DPX and imaged with an LSM-700 confocal microscope (Carl Zeiss).

Immunohistochemistry for protein markers of immune cells. Control and injured Thy1-eYFP-H mice ( $n=5$ per group) were perfused with $4 \%$ PFA $48 \mathrm{~h}$ after injury. Sagittal brain sections $(40 \mu \mathrm{m})$ were processed in series for fluorescent IHC addressing select immune cell markers: P2Y12 (1:1000; AnaSpec catalog \#AS55043A, RRID:AB_2298886), CD68 (1:200; Abbiotec catalog \#250594), and F4/80 (1:300; Abcam catalog \#ab16911, RRID: AB_443548). Immunofluorescence was performed essentially as described in previous sections. Secondary antibodies were all used in a 1:200 concen- 

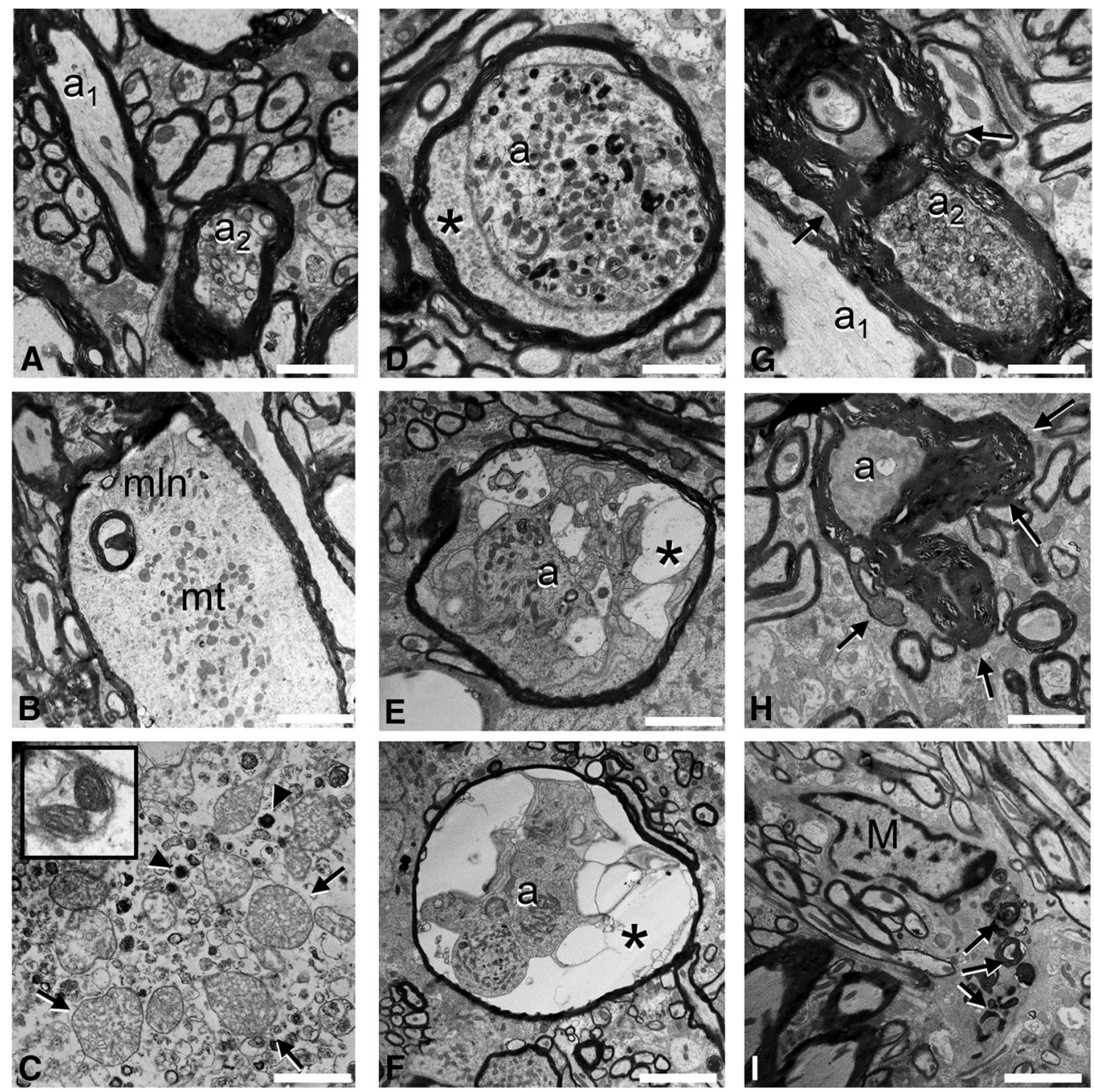

Figure 6. Ultrastructural profiles of damaged corticospinal axons $24 \mathrm{~h}$ after IA, including changes in the axoplasm $(\boldsymbol{A}-\boldsymbol{F})$ and the myelin sheath $(\boldsymbol{G}, \boldsymbol{H})$. Key axons are labeled with "a" everywhere. $\boldsymbol{A}$, Differentiation between normal corticospinal axons (e.g., $\mathrm{a}_{1}$, left top) and damaged axons (e.g., $\mathrm{a}_{2}$, center bottom), in the early stages of axonopathy. Scale bar, $1 \mu \mathrm{m} . \boldsymbol{B}$, Axoplasmic features of damaged axons in early stages. Note internalized myelin profiles $(\mathrm{mln})$ and accumulations of swollen mitochondria ( $\mathrm{mt})$. Scale bar, $500 \mathrm{~nm}$. C, Swollen mitochondria as in $\boldsymbol{B}$ shown here at higher magnification, along with dark inclusions that are characteristic of traumatic axonopathy in relatively early stages. Inset, Normal mitochondria of an uninjured axon are shown for comparison. Scale bar, $50 \mathrm{~nm}$. D, Here we show a paranodal region ( ${ }^{*}$ oligodendrocyte cytoplasm), with accumulations of abnormal organelles and dark inclusions. Scale bar, $500 \mathrm{~nm}$. $\boldsymbol{E}, \boldsymbol{F}$, Degenerating axoplasmic features. Note a breakdown of axoplasmic structure, with the formation of vacuoles of various sizes, from relatively small $(\boldsymbol{E})$ to large $(\boldsymbol{F})\left(^{*}\right)$. Scale bar, $500 \mathrm{~nm}$. $\boldsymbol{G}, \boldsymbol{H}$, Abnormal myelin profiles in advanced degeneration (arrows). $\mathbf{G}$, Note the difference between a normal appearing $\left(\mathrm{a}_{1}\right)$ and degenerating $\left(\mathrm{a}_{2}\right)$ axons. Scale bar, $1 \mu \mathrm{m}$. $\mathbf{I}, \mathrm{A}$ characteristic macrophage (M) with dark inclusions (arrows) in the CST. Scale bar, $1 \mu \mathrm{m}$.

tration and included Cy3 donkey anti-rabbit IgG (Jackson ImmunoResearch Laboratories catalog \#711165152) for P2Y12 and CD68 antibodies and Cy3 donkey anti-rat IgG (Jackson ImmunoResearch Laboratories cata$\log \# 712165153)$ for the F4/80 antibody. Sections were counterstained in DAPI and coverslipped in DPX. Sections were imaged with an Axioplan microscope (Carl Zeiss) and a LSM-700 confocal microscope (Carl Zeiss).

Statistical analyses. Statistical analyses were performed using Prism 4 (GraphPad Software) and results are expressed as mean \pm SEM. Student's $t$ test was used for single comparisons. One-way ANOVA with Tukey post hoc testing was used for multiple comparisons. In all cases, statistical significance was set at $p<0.05$.

\section{Results}

The diffuse, multifocal nature of IA injury

To characterize the IA model from a biomechanical perspective, we imaged the injury process with a high-frame rate camera, shooting at 20.000 frames per second for the whole duration of the movement of the mouse head (Fig. 1A). Head motion was confined to the sagittal plane and was consistent among IA ses- sions. As shown in Figure $1 A$, the head was subjected to both translational and angular (rotational) acceleration, first downward into the foam bed of the IA apparatus and then upward to a nearly vertical position. With $60 \mathrm{~g} \times 1 \mathrm{~m}$ impact, the duration of head movement was $\sim 150 \mathrm{~ms}$ and the resulting velocity was 4.1 $\mathrm{m} / \mathrm{s}$. The placement of the metallic disc on the skull prevented fractures in all cases.

To assess the possible effects of IA on brain parenchyma at the impact site (area under the disc) we processed tissues with H\&E for general pathology, and Perls' Prussian blue for ferric iron (parenchymal blood). Overall, we found no evidence of cytoplasmic eosinophilia or nuclear pyknosis of cortical neurons. Cortical structure was intact everywhere, including motor, sensory, and parietal cortical areas under the disc. We found no cortical staining with Perls' iron, but we did see a weak diffuse signal in the mesencephalic flexure of brainstem, (Fig. 1B). In addition, the CA1 field of hippocampus was free of eosinophilic neurons, a pattern consistent with absence of significant brain hypoxia (Fig. 1C). 

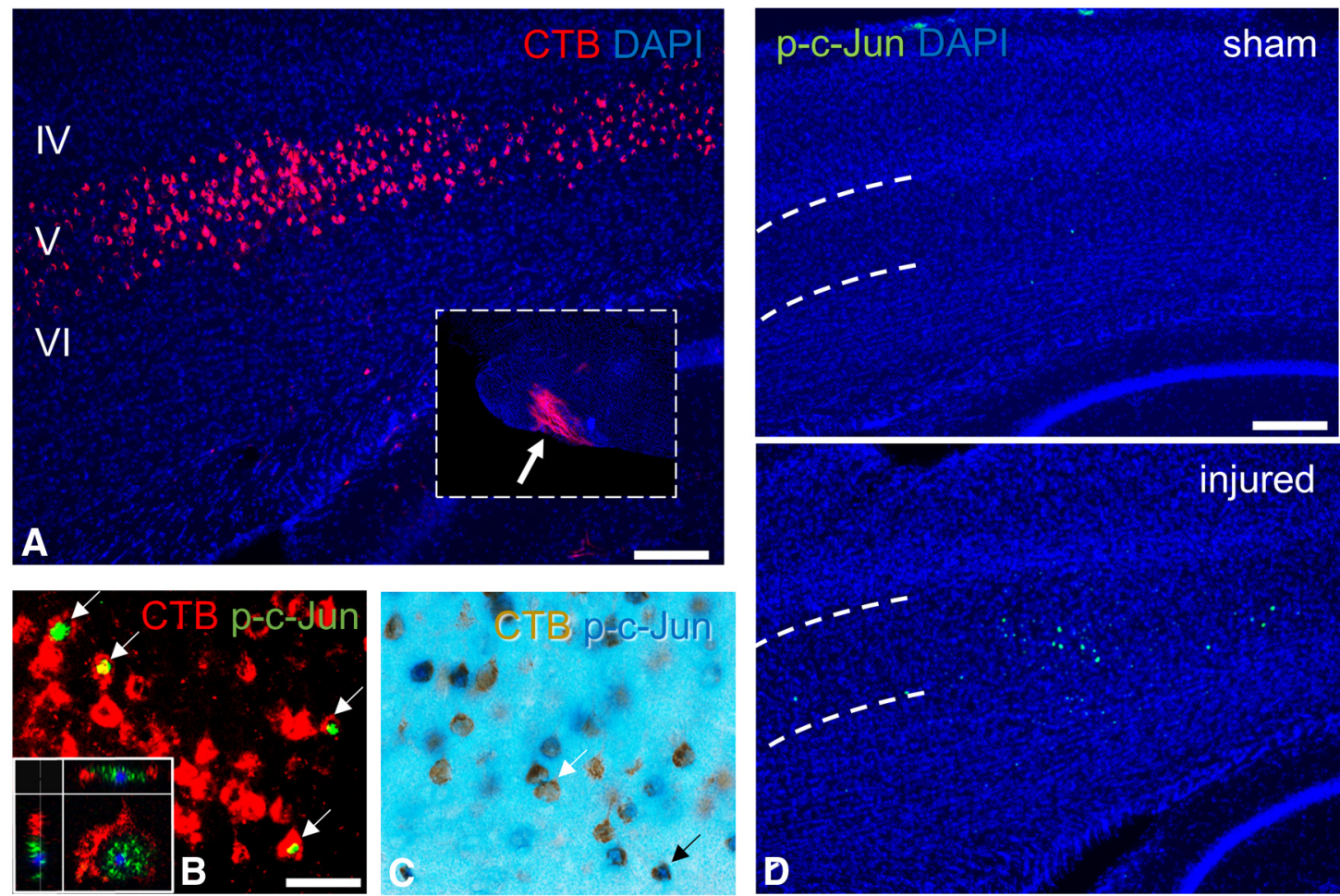

Volume of layer $\mathrm{V}$ pyramidal neurons

Volume of p-c-Jun
pos (+) vs neg (-)

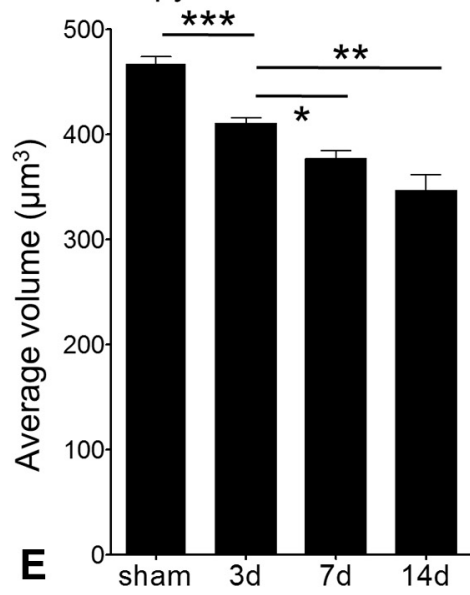

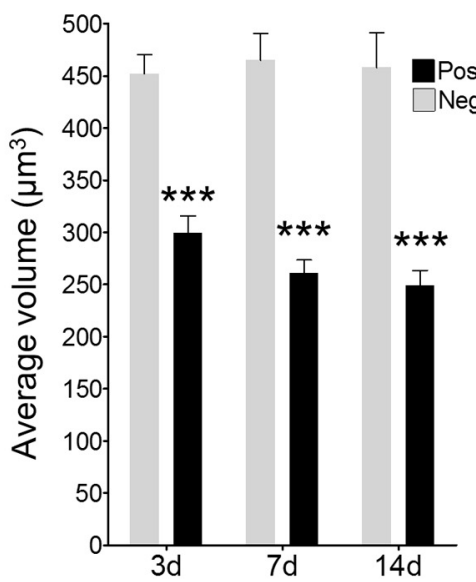

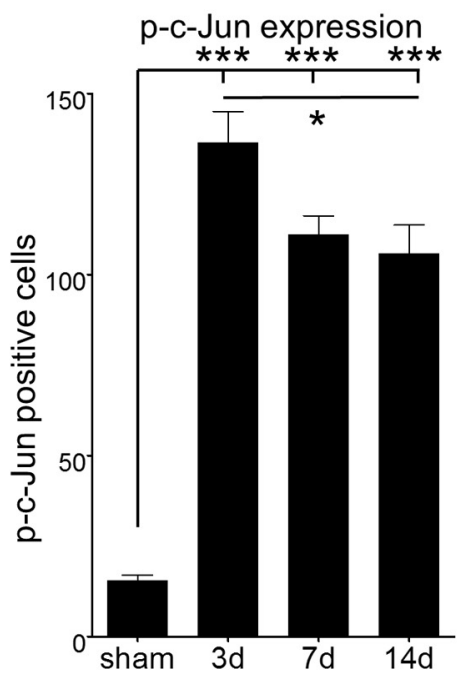

Figure 7. Retrograde changes in axotomized corticospinal neurons include c-Jun phosphorylation and perikaryal atrophy. $A$, Injection of the retrograde label CTB in the ponto-medullary junction (inset) leads to robust perikaryal labeling of corticospinal layer V pyramidal neurons. Scale bar, $80 \mu \mathrm{m} . \boldsymbol{B}, \boldsymbol{C}$, Axonal injury is associated with phosphorylation of c-Jun in the nucleus of CST layer V pyramidal neurons ( $\boldsymbol{B}, \boldsymbol{C}$, arrows). There is perikaryal atrophy in double-labeled neurons compared with neurons that do not express $\mathrm{p}$-c-Jun. $\boldsymbol{B}$, Inset, Confocal image of a double-labeled neuron. Scale bar, $50 \mu \mathrm{m}$. D, Phosphorylated c-Jun expression (shown here $3 \mathrm{~d}$ after IA) is confined to layer $V$ and is specific to injured animals (bottom). Scale bar, $100 \mu \mathrm{m}$. $\boldsymbol{E}$, These three panels show the course of retrograde changes in identified corticospinal pyramidal neurons at 3, 7, and $14 \mathrm{~d}$ after injury based on perikaryal volume (left), $\mathrm{p}$-c-Jun expression (right), and comparison in perikaryal volume between $\mathrm{p}-\mathrm{c}-\mathrm{Jun}(+)$ and $\mathrm{p}-\mathrm{c}-\mathrm{Jun}(-)$ neurons (middle; reflecting the relationship between atrophy and $\mathrm{p}-\mathrm{c}-\mathrm{Jun}$ immunoreactivity). Error bars indicate mean $\pm \mathrm{SEM}$. Group values were analyzed with one-way ANOVA followed by Tukey's post hoc testing for multiple comparisons or Student's t test for single comparison analysis: ${ }^{*} p<0.05 ;{ }^{* *} p<0.01 ;{ }^{* * *} p<0.001$.

Using brain sections from $Y F P-H$ mice and fluorescence microscopy, we found axonal abnormalities at multiple sites in the forebrain, diencephalon, midbrain, medulla, and the cervical spinal cord (Fig. 2). These abnormalities consisted mainly of varicosities or axon bulbs and, more rarely, axonal vacuolation or trails of intensely fluorescent small axon fragments suggestive of Wallerian degeneration. In an approximately rostrocaudal order, major white matter tracts exhibiting such abnormalities included the precommisural and postcommisural fornix, the habenulointerpeduncular tract, the lower CST, the reticulospinal tract (RST), and the gracile fasciculus. In view of the fact that in the
$Y F P-H$ transgenic line used here only certain populations of projection neurons are labeled, it is likely that more white matter tracts become involved in IA injury within the parameters used in the present study (Xu et al., 2016).

Various axonal tracts involved in IA injury show somewhat distinct pathologies. Axonal profiles in the CST, measuring 3-6 $\mu \mathrm{m}$ in diameter, are described in the next section. For example, in the RST, fragmentation profiles suggestive of Wallerian degeneration are evident as early as $24 \mathrm{~h}$ after injury (Fig. 2C) and increase at $48 \mathrm{~h}$. Many RST axons show large varicosities $(8-10 \mu \mathrm{m}$ in diameter) and some show vacuolations. The gracile fasciculus 
develops numerous characteristic large varicosities $(12-15 \mu \mathrm{m}$ in diameter) both in the course of this tract in the dorsal spinal cord-medulla and at the terminal fields in the gracile nucleus; the number and size of these lesions cause them to stand out in sagittal sections of the brainstem (Fig. 2D). In the fornix, axonal abnormalities take the form of numerous small (1- $\mu \mathrm{m}$-diameter) spheroids distributed near or at the terminal fields of the precommissural and postcommissural fornix in the septum and mammillary bodies, respectively (Fig. $2 E, F$ ). Lesions are present as early as $3 \mathrm{~h}$ after injury, and they increase in number at 24 and $48 \mathrm{~h}$.

To further characterize the IA injury, we established the presence and early time course of microvascular injury (i.e., BBB breakdown). To this goal, we labeled endothelial cells with LEA via intracardial injection immediately before perfusion fixation and then immunostained sections with mouse anti-IgG antibody at early time points after injury (i.e., $15 \mathrm{~min}, 1 \mathrm{~h}$, and $2 \mathrm{~h}$ ). In well-perfused subjects, IgG immunoreactivity in brain parenchyma indicates leakage of plasma from brain capillaries and thus serves as a marker of BBB degradation (Wang et al., 2011; Xu et al., 2016). We found IgG immunoreactivity outside brain capillaries as early as $15 \mathrm{~min}$ after IA injury (Fig. 3). IgG leakage was restricted to the brainstem and was especially severe in the region of mesencephalic flexure, a pattern suggesting a primary effect of IA on that part of the brain (Fig. $3 A$ ). Under high magnification, sections with IgG and LEA labeling show unambiguous IgG localization outside the endothelium (Fig. $3 B-D$ ).

A key aspect of traumatic axonopathy is the neuroinflammatory macrophagic response. To characterize the main features of this response in our model, we performed IHC for the representative microglial and macrophage protein epitopes P2Y12, CD68, and F4/80 $48 \mathrm{~h}$ after IA injury (Fig. 4). P2Y12, a metabotropic ADP receptor, is constitutively expressed in abundance in microglial cells (Haynes et al., 2006; Kobayashi et al., 2008). In our material, P2Y12 immunoreactivity was present in resting microglial cells throughout the brain. P2Y12 $(+)$ cells with hypertrophic cell bodies characteristic of activated microglial cells were numerous in certain brainstem sites, including the area of inferior olive at the crossing of pyramids with the RST and the pyramidal decussation (i.e., regions with dense axonal lesions) (Fig. $4 C$ ). These activated cells had thick, short processes instead of the ramified appearance of resting microglia and formed clusters of two to four cells (Fig. 4C, inset 1) or had stout thorny processes typical or phagocytes (Fig. 4C, inset 2) (Yamada and Jinno, 2013). In addition to the CST, activated microglia was present in fornix, corpus callosum, gracile nucleus, and cerebellum, all areas associated with axonal injury after IA (Xu et al., 2016). In the CST, activated microglia and peripheral macrophages abound at the pyramidal decussation and CST $\times$ RST, where there is a majority of axonal abnormalities, but were not detected in CST axon segments that do not show pathology, such as cortex, internal capsule, peduncles, or pons. Activated microglial cells were also labeled with IHC for CD68, a lysosomal protein that is highly expressed in activated microglia. As in the case of P2Y12, CD68 labeling was especially strong in lower pyramids and the pyramidal decussation (Fig. $4 A, B, G$ ). We also explored the presence of infiltrating blood-borne macrophages with the marker F4/80. Such F4/80 (+) macrophages were absent in the brain parenchyma of uninjured mice. Forty-eight hours after IA injury, F4/ 80 -positive macrophages had made their appearance in the brain parenchyma, forming clusters around capillaries close to injured CST axons (Fig. 4D,E).

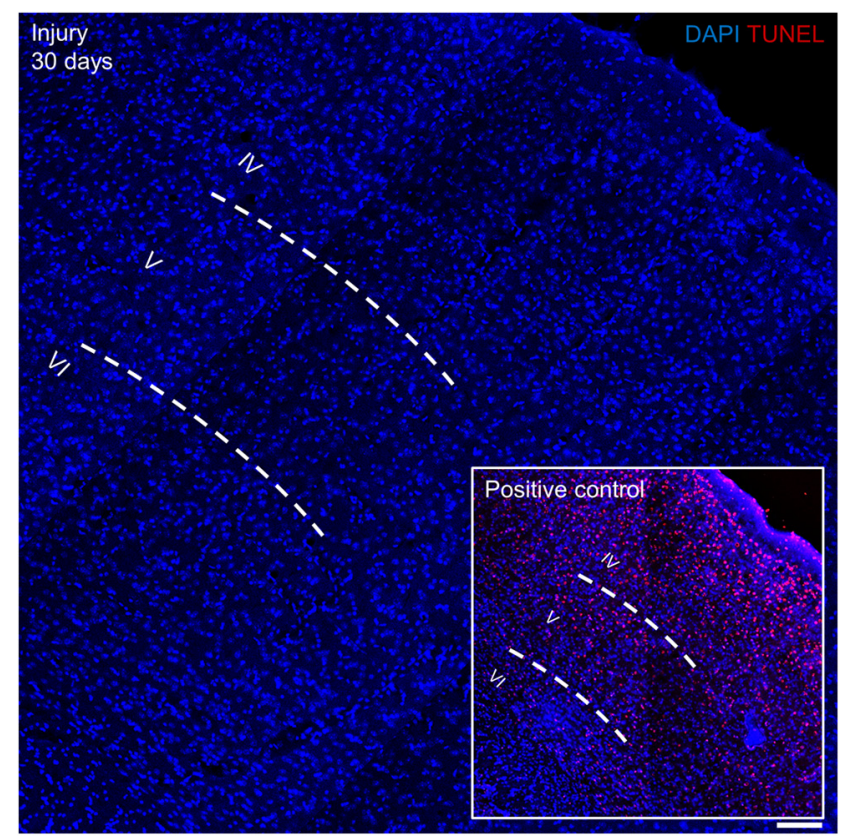

Figure 8. A representative TUNEL preparation through motor cortex shows the absence of cell death of cortical neurons after IA injury. This section is taken from an injured mouse $30 \mathrm{~d}$ after injury. Inset, Positive control section from an uninjured mouse after treatment with DNase I. Scale bar, $50 \mu \mathrm{m}$.

In conclusion, IA produces diffuse primary axonal injury accompanied by BBB disruption and neuroinflammation comprised of both resident and blood-borne macrophage response. The initial shearing stress is especially evident in the brainstem, as shown by the anatomical distribution of early $\mathrm{BBB}$ impairments. The Thy1-eYFP-H transgenic line offers remarkable detail on the location of axonal injury, the distinct cytologies of axonal lesions in various tracts, as well as the longitudinal evolution of axonopathy.

\section{The nature and severity of axonal abnormalities in the CST}

Based on observations in YFP- $H$ mice, axonal abnormalities in the CST occurred almost exclusively at brainstem and spinal levels. We did not see such abnormalities in cortex, internal capsule, or cerebral peduncles. Most lesions were axonal varicosities or end bulbs at the level of the pyramids and the pyramidal decussation (Fig. 2A). In many cases, multiple varicosities or varicosities and bulbs coexisted within the same axon. Abnormalities in the spinal cord were seen along the dorsal CST (Fig. 2B). Many axons formed classical retraction balls (i.e., disconnected spherical formations that are distinct from bulbs that may be still attached to distal atrophic axons). Confocal microscopy and edge detection analysis confirmed the presence of multiple varicosities on single axons and showed high concentration of spherical organelles at sites of axonal bulging (Fig. $5 B-B^{\prime}$ ). Based on counts of YFP $(+)$ axonal varicosities in cross sections of pyramids, the severity of axonal pathology in the CST is related to IA burden (Fig. $5 C$ ). There is a $2 \times$ and $3 X$ increase in the number of lesions when weight in the IA device advances from 20 to 40 and from 40 to $60 \mathrm{~g}$, respectively.

The ultrastructural analysis of tissue at the level of lower pyramids/pyramidal decussation shows that axonal swellings identified with fluorescent microscopy correspond to sites of axonal degeneration. Degenerative changes include severe alterations in overall axon structure, organelles, the axoplasm, and the myelin 
sheath (Fig. 6). In such cases, axons are condensed with degraded or absent neurofilament or microtubule architecture. Other axons are filled with tightly packed electrondense bodies and damaged, swollen mitochondria without clearly delineated cristae (Fig. 6C). Many axons are abnormally large, with vacuoles in the axoplasm and separation of axoplasm from the axolemma. Myelin pathology was also present, with myelin intrusions, excess myelin figures, and abnormal thickening of the myelin sheath. Macrophages with dark inclusions were frequently apposed to degenerating axons (Fig. 6I). Also, intact axons were interspersed among degenerating axons, a pattern characteristic of DAI.

In summary, the CST is severely afflicted during IA of the head, and severity of axonopathy can be titrated based on severity of impact.

\section{Retrograde changes in corticospinal neurons: c-Jun phosphorylation and atrophy}

To identify pyramidal neurons whose axons were injured in the lower pyramidal tract, we explored the presence and cytology of corticospinal neurons in frontal neocortex that also expressed phosphorylated c-Jun (Fig. 7). The cell bodies of neurons projecting in the CST were identified by retrograde filling with the tracer CTB injected into the ponto-medullary junction (Fig. 7A). Phosphorylation of c-Jun in the nuclei of corticospinal neurons was examined with immunohistochemistry (Fig. $7 B, C$ ). Corticospinal neurons were studied at 3,7 , and $14 \mathrm{~d}$ after injury, covering the period from the induction of c-Jun phosphorylation early on to later changes in perikaryal volume. We explored three specific trends: time course of volume changes in CTB-labeled perikaryal, time course of phosphorylated c-Jun expression, and rates of $\mathrm{p}$-c-Jun expression in atrophic and normal layer $\mathrm{V}$ pyramidal neurons.

We found that $10 \mathrm{~d}$ after injection into the ponto-medullary portion of CST, CTB strongly labels layer $\mathrm{V}$ pyramidal neurons in frontal neocortex (Fig. 7A). Retrogradely labeled pyramidal profiles in subjects injured with IA were significant smaller than pyramidal profiles in sham animals at all three time points; for example, at $3 \mathrm{~d}$, average volume was reduced by $12 \%$, whereas at $14 \mathrm{~d}$ average volume was reduced by $26 \%$ (Fig. 7E). Phosphorylated c-Jun immunoreactivity was upregulated after axonal injury, and it was most profound at $3 \mathrm{~d}$ after injury with the signal decreasing slightly at later time points (Fig. $7 D, E$ ). In addition, at all three time points, perikaryal volume was significantly smaller in neurons expressing p-c-Jun compared with the ones with normal volume, a pattern suggesting a relationship between $\mathrm{p}$-c-Jun expression and perikaryal atrophy (Fig. 7C-E). Based on the negative TUNEL staining for neuronal cell death at $3,7,14$, and $30 \mathrm{~d}$

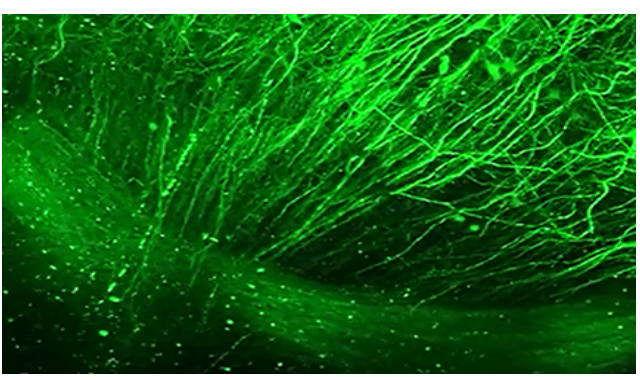

Movie 1. A 3D reconstructed cleared whole Thy1-eYFP-H mouse brainstem after IA injury at single-axon resolution. The CST, RST, and gracile fasciculus, all with injured axons, are shown.

.
Brain Stem $3 \mathrm{D}$ rendering

A
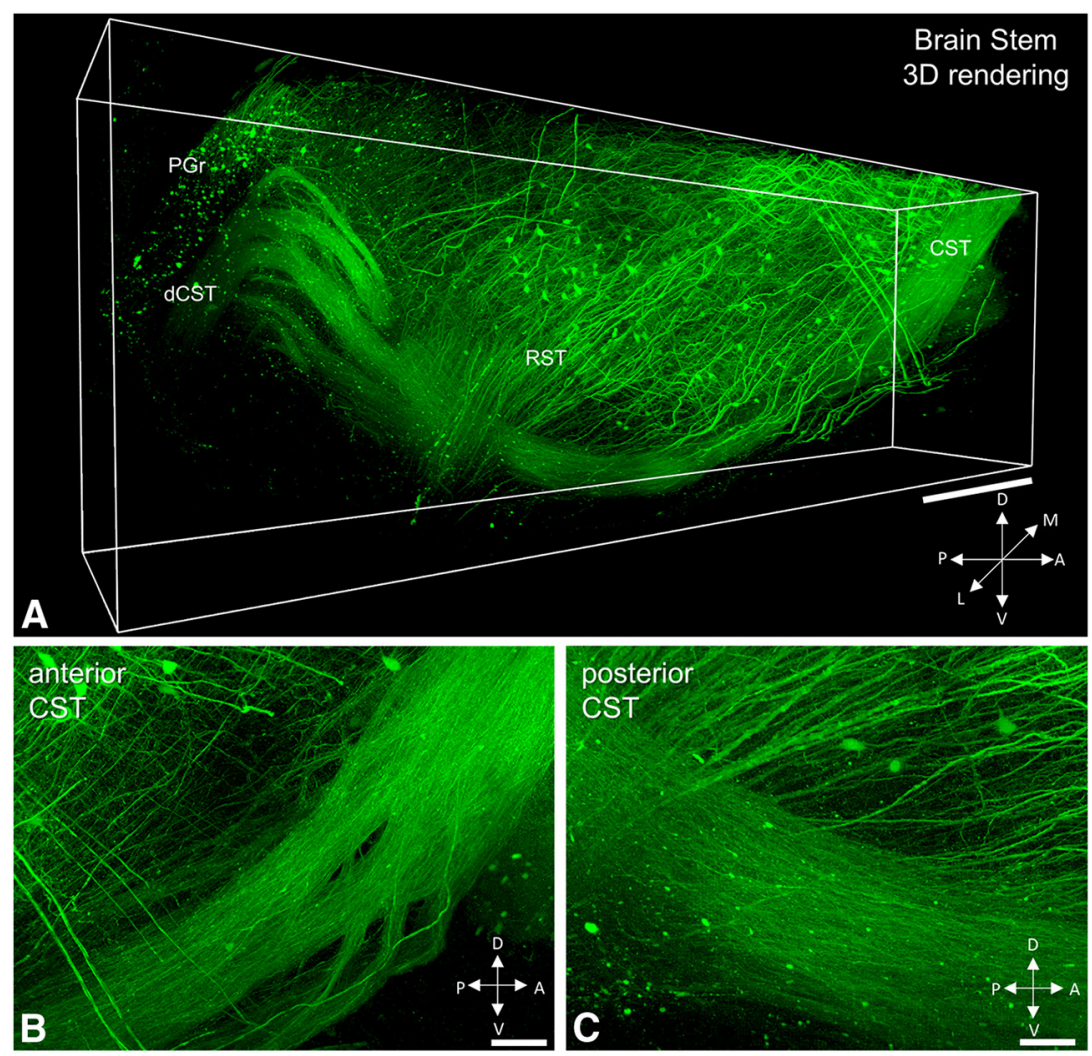

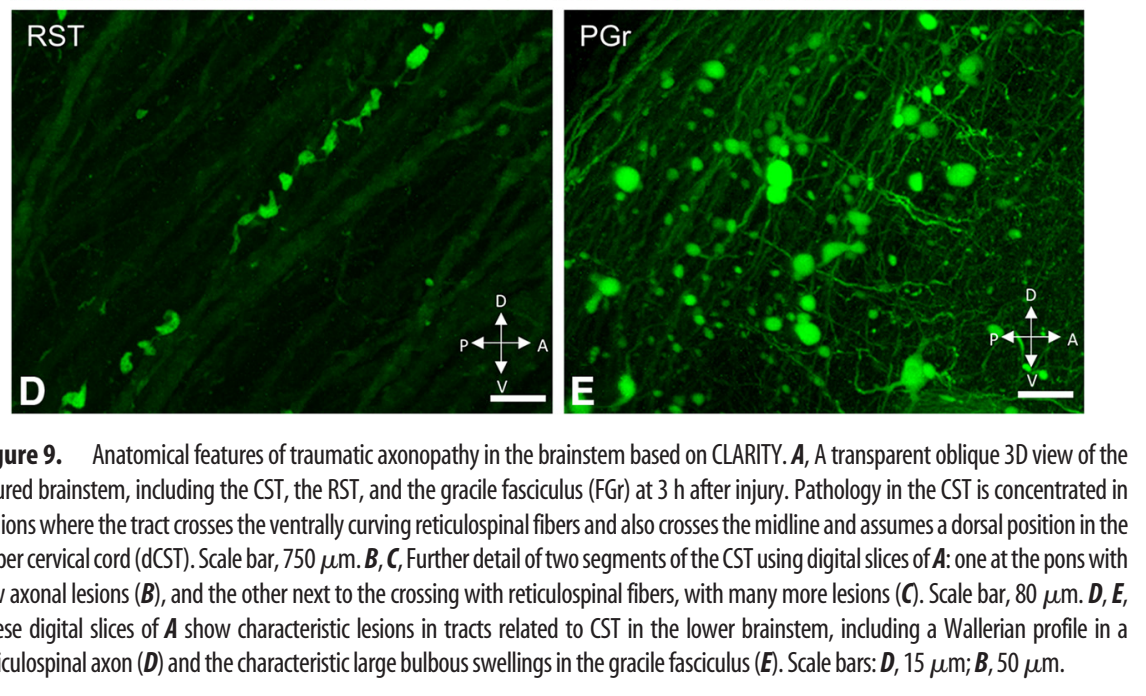

Figure 9. Anatomical features of traumatic axonopathy in the brainstem based on CLARITY. A, A transparent oblique 3D view of the injured brainstem, including the CST, the RST, and the gracile fasciculus (FGr) at $3 \mathrm{~h}$ after injury. Pathology in the CST is concentrated in 列 few axonal lesions $(\boldsymbol{B})$, and the other next to the crossing with reticulospinal fibers, with many more lesions ( $\boldsymbol{C}$ ). Scale bar, $80 \mu \mathrm{m} . \boldsymbol{D}, \boldsymbol{E}$, These digital slices of $\boldsymbol{A}$ show characteristic lesions in tracts related to CST in the lower brainstem, including a Wallerian profile in a reticulospinal axon $(\boldsymbol{D})$ and the characteristic large bulbous swellings in the gracile fasciculus $(\boldsymbol{E})$. Scale bars: $\boldsymbol{D}, 15 \mu \mathrm{m} ; \boldsymbol{B}, 50 \mu \mathrm{m}$.

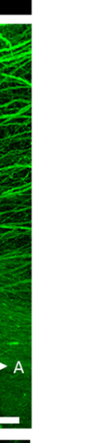



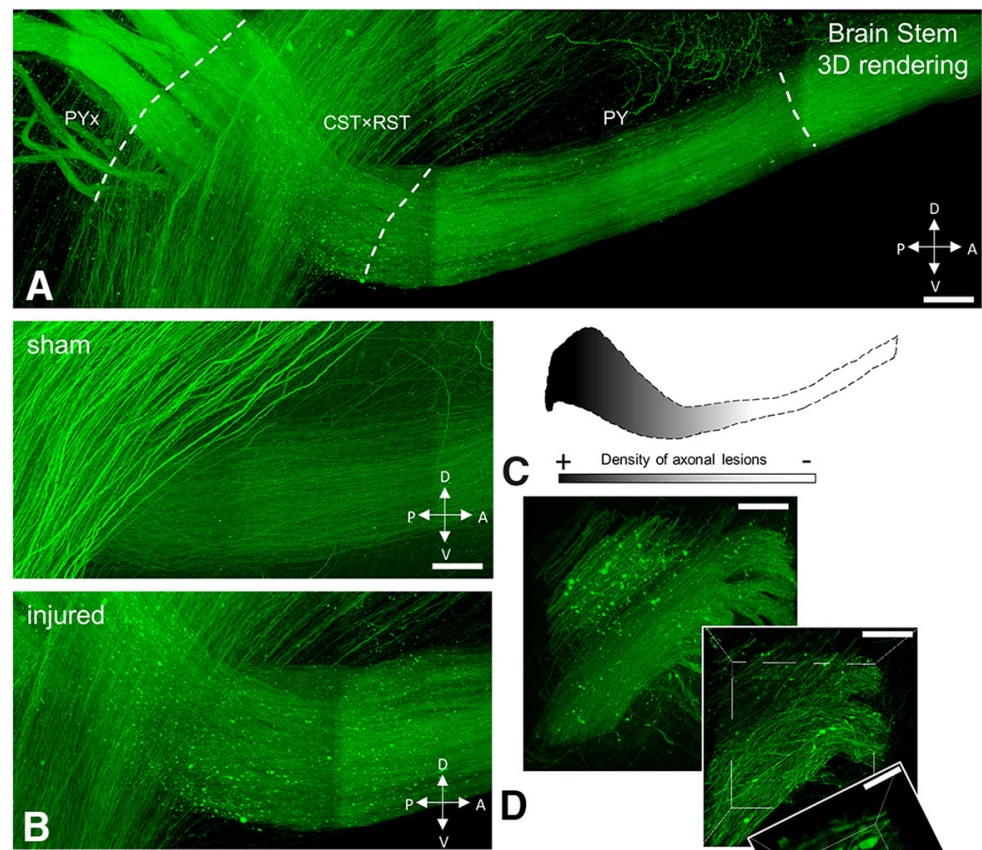

C +
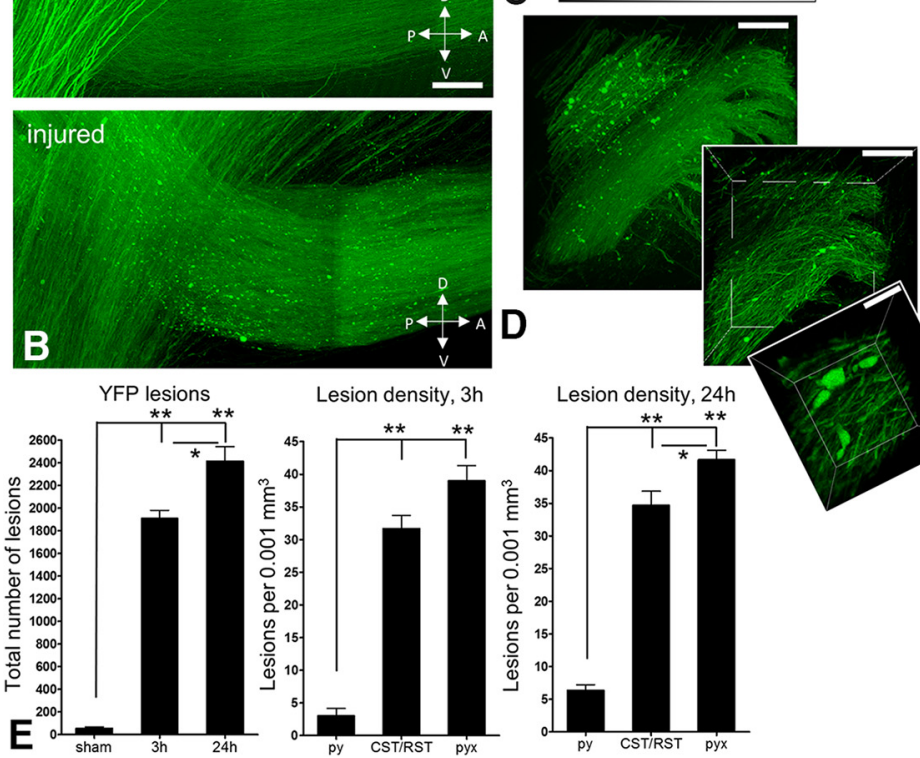

Lesion density, $3 \mathrm{~h}$
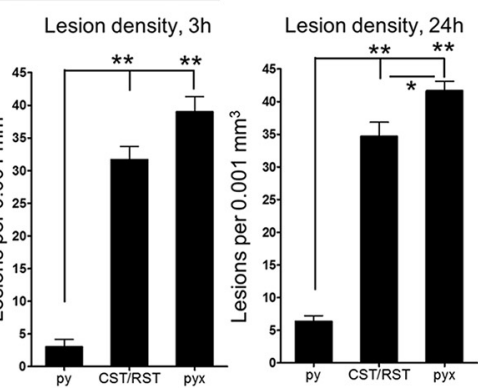

Figure 10. Quantitative analysis of CST lesions based on CLARITY. $A, B, A$ sagittal image of a cleared brainstem focusing on the CST and showing the concentration of axonal lesions toward the CST $\times$ RST junction and decussation $(A)$. The CST $\times$ RST junction in $(\boldsymbol{A})$ is further enlarged in the bottom left panel $(\boldsymbol{B})$ and apposed to a sham brainstem shown on top. $\boldsymbol{C}, A$ computerized graphic of lesion density, based on the spot detection function. $\boldsymbol{D}$, Progressive magnification of the $3 D$ dataset showing the clear distinction of individual axonal lesions in the native resolution of the image acquisition. Scale bars: $\boldsymbol{A}, 150 \mu \mathrm{m} ; \boldsymbol{B}, 180 \mu \mathrm{m} ; \boldsymbol{D}$ (starting from top), $150 \mu \mathrm{m}, 70 \mu \mathrm{m}, 10 \mu \mathrm{m}$, respectively. $\boldsymbol{E}$, Counts of total numbers of axonal lesions based on time ( 3 and $24 \mathrm{~h}$ after injury) (left), and on location, such as crossing with reticulospinal axons and the decussation at 3 (middle) and 24 (right) hours after injury. Error bars indicate mean \pm SEM. Group values were analyzed with one-way ANOVA followed by Tukey's post hoc testing: ${ }^{*} p<$ $0.05 ;{ }^{* *} p<0.001$.

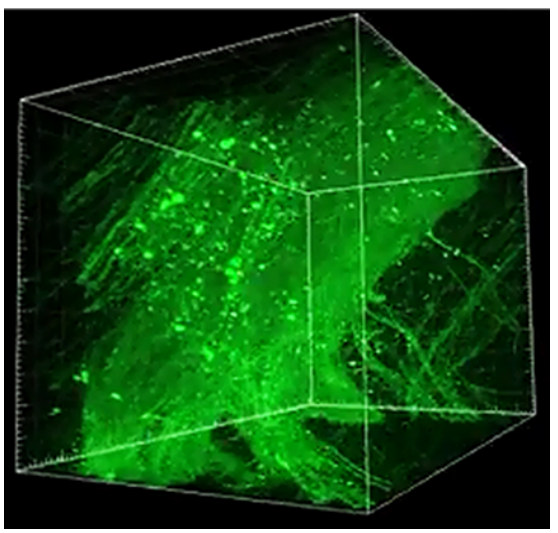

Movie 2. A $3 D$ reconstructed pyramidal decussation from a cleared mouse brainstem after IA injury. Note the single-axon resolution and the preservation of signal intensity throughout the entire volume. Single axonal lesions are evident and readily recognized, allowing the quantification of the total number of axonal lesions in the entire CST. after IA, layer $V$ pyramidal neurons do not die up to a month after injury (Fig. 8).

In conclusion, CST neurons with injured axons become atrophic after injury, but they do not undergo cell death.

\section{CLARITY-based quantitative analysis of axonal injury in the CST}

To characterize the full 3D extent of axonal injury in the CST, we rendered the brainstem transparent with CLARITY and examined cleared tissues with highresolution 2-photon microscopy coupled with a CLARITY-optimized objective. These strategies allowed us to resolve individual axons at $25 \times$ magnification and generated a sharp 3D visualization of axonal tracts coursing in the brainstem from the level of the lower cerebral pedunclepons to the dorsal columns of the cervical spinal cord (Fig. 9; Movie 1). Based on the YFP expression pattern in Thyl-YFP-H mice, the main pathways that can be visualized are the CST, the RST, and the gracile fasciculus. All three tracts developed axonal abnormalities and these lesions were sharply visualized across the entire thickness of the brainstem, allowing for an impressive reconstruction of the location and magnitude of the injury effect (Fig. 9A). Moreover, the combination of 2-photon microscopy, HyD detectors in the nondescanned position, and a longworking-distance objective with high numerical aperture revealed important pathological features of individual lesions (Fig. 9B-E).

The high-resolution $3 \mathrm{D}$ reconstruction of brainstem over a distance of $6 \mathrm{~mm}$ provided raw data for counting the total number of axonal abnormalities in distinct CST segments in the medullary pyramids, at the crossing of CST with the RST (CST $\times$ RST), and at the level of pyramidal decussation (Fig. 10A-D). Using such data (Movie 2), we found that the total number of axonal abnormalities increased significantly from 3 to $24 \mathrm{~h}$ after injury (Fig. 10E). The density of axonal abnormalities varies among regions: it is low at the main body of the pyramid, high at CST $\times$ RST, and even higher at the level of the pyramidal decussation; density increases across regions from 3 to $24 \mathrm{~h}$ after injury, but the differential involvement of these regions remains the same (Fig. 10E). The rostrocaudal progression of lesion severity is impressive (Fig. 10C).

CLARITY-based IHC for APP, the standard molecular marker of axonal injury, was used to compare between the number of lesions detected with this marker and YFP $(+)$ lesions in the brainstem at two time points after injury: i.e., 3 and $24 \mathrm{~h}$ (Fig. $11 A-D$; Movie 3). APP $(+)$ lesions were numerous at $3 \mathrm{~h}$ and decreased significantly at $24 \mathrm{~h}$ (Fig. $11 D$ ), in contrast to YFP $(+)$ lesions that increased from 3 to $24 \mathrm{~h}$ (Fig. 10E). The total number of APP $(+)$ lesions was smaller than YFP $(+)$ lesions across all time points (Fig. 10E, left, vs Fig. 11D, left). The density of APP 
$(+)$ abnormalities was counted in the pyramids, at CST $\times$ RST, and at the pyramidal decussation. Areas with highest density were the decussation, followed by CST $\times$ RST, a pattern similar to the one encountered with YFP axonal abnormalities. These data show that YFP reveals a larger number of axonal abnormalities than APP labeling and has a different time course, perhaps due to the accumulation of structural pathology in the first $24 \mathrm{~h}$ period.

Our results indicate the presence of progressive axonopathy that is maximal at the pyramidal decussation and they establish CLARITY as a robust quantitative methodology for studying TAI in the mouse brain. Markers of axonal injury that detect anterogradely transported proteins (i.e., APP) may be less representative of the problem than YFP, which is encoded by a stably expressed transgene with robust labeling of the axoplasm.

\section{Genetic or pharmacological} interference with SARM1 signaling ameliorates early axonal pathology Here we took advantage of the resolution and quantitative capabilities of CLARITY to explore the role of the NMNAT2SARM1 pathway of axonal self-destruction in traumatic axonopathy (Figs. 12, 13). The anterograde transport blockage in injured axons prevents the labile axon maintenance factor NMNAT2 from reaching the distal axon, thus triggering SARM1depended axonal degeneration (Gilley et al., 2010; Osterloh et al., 2012; Gerdts et al., 2015, 2016; Hill et al., 2016; Summers et al., 2016; Walker et al., 2017, Essuman et al., 2017). SARM1 is a NADase that is dormant in uninjured axons in the presence of NMNAT2. When NMNAT2 is depleted after injury, SARM1 becomes activated and consumes axonal $\mathrm{NAD}^{+}$, causing axonal degeneration. The products of the enzymatic activity of SARM1 are Nam and ADP-ribose. Of these products, Nam is a potent inhibitor and regulates SARM1 activity via negative feedback (Fig. 12A).

To establish the involvement of the NMNAT2-SARM1 pathway in the early stages of axonal degeneration after TAI, we generated Thy1-eYFP-H mice in which SARM1 was deleted (Thy1-eYFP-H/SARM1 ${ }^{-1-}$ ). These mice have precisely the same pattern of YFP expression as Thy1-eYFP-H mice. Thy1-eYFP-H/ $S A R M 1^{-1-}$ and Thy1-eYFP-H/SARM1 ${ }^{+/+}$were injured with IA and brains were processed with CLARITY at $24 \mathrm{~h}$ after injury (Fig. $12 B)$. We counted the total number of axonal lesions in the CST from pons to cervical cord and regional densities of abnormalities as in the previous section. We found that $S A R M 1^{-1-}$ mice had a significantly lower total number of CST lesions compared with
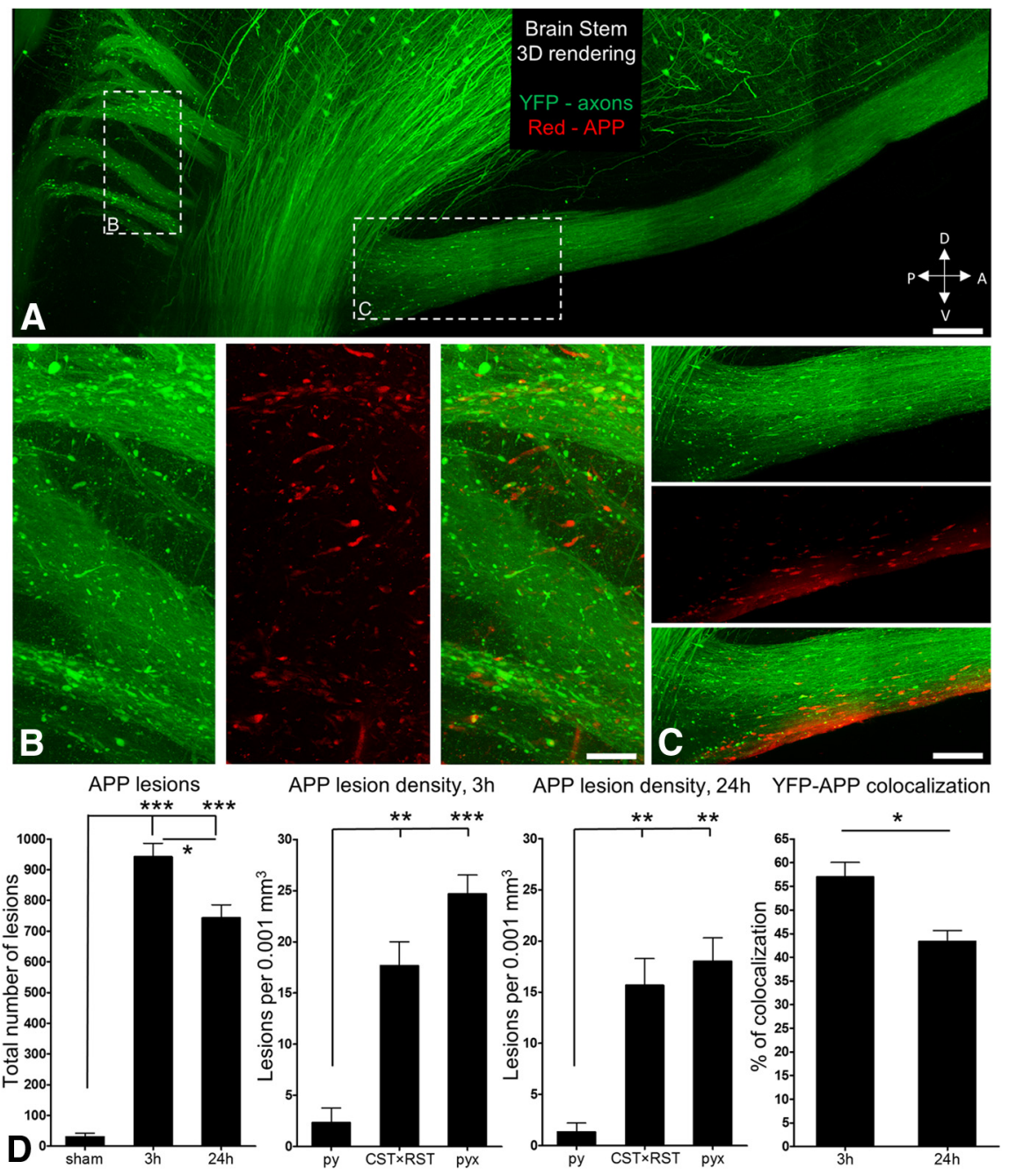

Figure 11. Comparison between YFP-based and APP-labeled axonal lesions with CLARITY at 3 and $24 \mathrm{~h}$ after injury. $\boldsymbol{A}, \mathrm{A}$ sagittal view of a cleared brainstem preparation that was also processed for APP IHC (red), visualized here with 2-photon microscopy. For YFP excitation, the 2-photon laser was tuned at $920 \mathrm{~nm}$ and for the APP at $780 \mathrm{~nm}$. Scale bar, $300 \mu \mathrm{m}$. Two digital slices from the 3D dataset represent magnifications of boxed areas in $A$, allowing the visualization of all ( $B$, $150 \mu \mathrm{m} ; \boldsymbol{C}, 200 \mu \mathrm{m}$. $\boldsymbol{D}$, Counts of total numbers of APP-immunoreactive abnormalities at 3 and $24 \mathrm{~h}$ after 作 were analyzed with one-way ANOVA followed by Tukey's (fourth graph): ${ }^{*} p<0.05 ;{ }^{* *} p<0.01 ;{ }^{* * *} p<0.001$

$S A R M 1^{+/+}$mice, and significantly lower concentrations of abnormalities at key CST segments (CST $\times$ RST, pyramidal decussation, and cervical cord). Density of lesions was greater at the cervical cord and decussation than CST $\times$ RST (Fig. 12C).

To explore the role of NMNAT2-SARM1 pathway in traumatic axonopathy with pharmacological means, we used FK866 to raise levels of Nam in the axonal compartment (Essuman et al., 2017). Nam participates in $\mathrm{NAD}^{+}$biosynthesis through an intermediate, NMN, a conversion catalyzed by NAMPT. In an injured axon, SARM1 activation depletes $\mathrm{NAD}^{+}$rapidly and the Nam produced is being converted to NMN very efficiently (Sasaki et al., 2016). Blocking NAMPT (e.g., with FK866) entraps Nam in injured axons and interferes with SARM1 activity (Fig. 12A). In our experiment, IA-injured Thyl-eYFP-H mice were treated with FK866 or vehicle and brains were processed with CLARITY (Fig. 


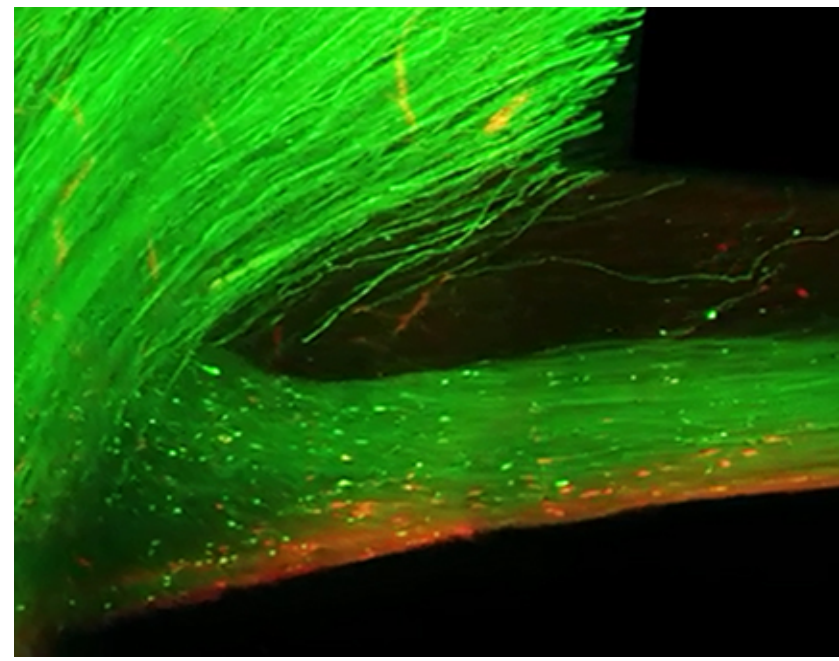

Movie 3. A3D reconstructed cleared Thy1-eYFP-H mouse brainstem $3 \mathrm{~h}$ after IA injury, after immunohistochemistry for APP. Note a similar distribution of YFP $(+)$ and APP-labeled axonal lesions, but with a higher absolute number of YFP $(+)$ lesions. For both YFP and APP, the areas with most lesions are the crossing of the CST with the RST and the pyramidal decussation.

13). The total number of axonal abnormalities in the CST from the pons to cervical spinal cord was counted $24 \mathrm{~h}$ after injury as in the previous section of the paper, and focusing on lower segments of the CST, including CST $\times$ RST, pyramidal decussation, and cervical cord (Fig. 13A,B). We discovered that FK866-treated mice had a significantly lower number of axonal lesions compared with vehicle-treated mice both in total and per anatomical segment, with a trend toward bigger difference in the cervical cord (Fig. 13C).

In summary, the activation of the NMNAT2-SARM1 pathway is a prominent mechanism of traumatic axonopathy with a significant role in early axonal degeneration. The robust qualitative and quantitative advantages of CLARITY make it a powerful tool in elucidating molecular mechanisms of axonal degeneration.

\section{Discussion}

Our findings show that IA produces multifocal primary axonopathy in diverse long tracts in the limbic, motor, sensory, and reticular activating systems. The use of high-resolution neuroanatomical tools, including Thy1-eYFP-H transgenic mice and CLARITY, offers new insights into mechanisms of diffuse TBI from head acceleration. CLARITY, in particular, followed by 3D reconstruction of axon tracts at single-axon resolution, has remarkable qualitative and quantitative advantages because it allows the precise localization of axonal lesions and the counting of all such lesions using spot detection analysis. In the case of CST, new insights gained from the implementation of these tools include the following: the vivid demonstration of the vulnerability of CST axons at a site of multiple crossings in the lower medulla, that is, the decussation of pyramids and intersection with the RST $(\mathrm{CST} \times \mathrm{RST})$; the atrophy, but not cell death, of neurons whose axons undergo degeneration after IA injury; the longitudinal evolution of lesions whose progressive increase in total number in the first $24 \mathrm{~h}$ after injury is a sign of ongoing axonopathy; and the protective effect of interfering with SARM1 signaling on early axonal lesions.

The IA model generates significant rotational acceleration of the mouse head, thus simulating a very common mechanism in human TBI (Zhang et al., 2006). As in previous work from our group (Xu et al., 2016), IA burden was set at a relatively mild range that completely avoids skull fracture, has near-zero mortality, and is consistent with the majority of cases of clinical TBI. Also, consistent with our previous publication (Xu et al., 2016), we found no pathology under the impact site, evidence that the principal mechanical event during IA is indeed acceleration of the head and impact serves mainly as the instrument to achieve it (Marmarou et al., 1994). Based on high-frame-rate camera recordings, it appears that acceleration occurs primarily at the sagittal plane as the head bounces back from the foam bed to a nearly vertical position in the course of $150 \mathrm{~ms}$. BBB permeability markers, such as IgG extravasation, suggest that this sagittal acceleration event preferentially disrupts brainstem anatomy but clearly also leads to primary axonal disruption in tracts rostral to the brainstem, for example, the fornix. The Thy1-eYFP-H mouse offers a vivid demonstration of the multifocal nature of primary axonal damage and implicates heretofore unmentioned pathways, such as the fornix, in diffuse TBI caused by IA. However, this transgenic strategy allows only the visualization of a subset of implicated pathways (Xu et al., 2016), constrained by the selective presence of YFP in projection neurons that express Thyl. Further experiments with mouse lines expressing GFP in additional populations of projection neurons (Feng et al., 2000) will form a more complete picture of the effect of IA on mouse brain. Thy1eYFP transgenic mice also reveal the cytological diversity of axonal lesions in various tracts, from the very small spheroids in precommissural and postcommissural fornix to the characteristically large preterminal bulbs in the gracile fasciculus. The resolution afforded by the stable presence of eYFP in the axoplasm also allows a dose-response study that directly demonstrates the relationship between IA burden and injury severity (i.e., external and internal injury "dose"). The resolving advantage of Thy1eYFP animals is apparent in the demonstrated differences between the central fluid percussion model that involves direct traumatic impact on the dura and generates proximal axonal lesions in pyramidal neurons (Greer et al., 2011) and our paradigm, in which primary lesions are distant from the pyramidal cell bodies.

As indicated in the previous paragraph, markers of BBB disruption indicate that the mechanical stress from IA is concentrated on the brainstem. High-resolution quantitative analysis of CST lesions based on CLARITY reveals that axonal pathology is especially severe in regions where the CST tract crosses other tracts (i.e., the RST) or itself makes major shifts in position (i.e., the area of pyramidal decussation). There is no evidence for the involvement of proximal axons or intermediate levels of CST in the basal ganglia, peduncles, or the pons. This finding has biomechanical implications because it suggests that, at sites of $3 \mathrm{D}$ complexity or intertwinement with other tracts, local shearing stress may be concentrated and amplified, resulting in focal axonal damage. This idea should be explored further in mouse lines with varied YFP expression patterns to include pathways not labeled in Thy1-eYFP-H (Feng et al., 2000). Although rotational acceleration has been shown to be the main mechanism responsible for brain deformation strain in the macro- and meso-scale with finite element modeling, our CLARITY-based high-resolution reconstructions add a microscopic level of analysis of strain vulnerability, allowing for microscale modeling of axonal injury (Zhang et al., 2006; Li et al., 2007).

CLARITY shows that TAI is a progressive phenomenon: it involves a lengthy secondary process after the initial event that justifies the term axonopathy used in this paper. In other words, 


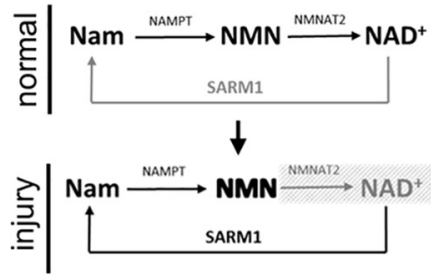

A
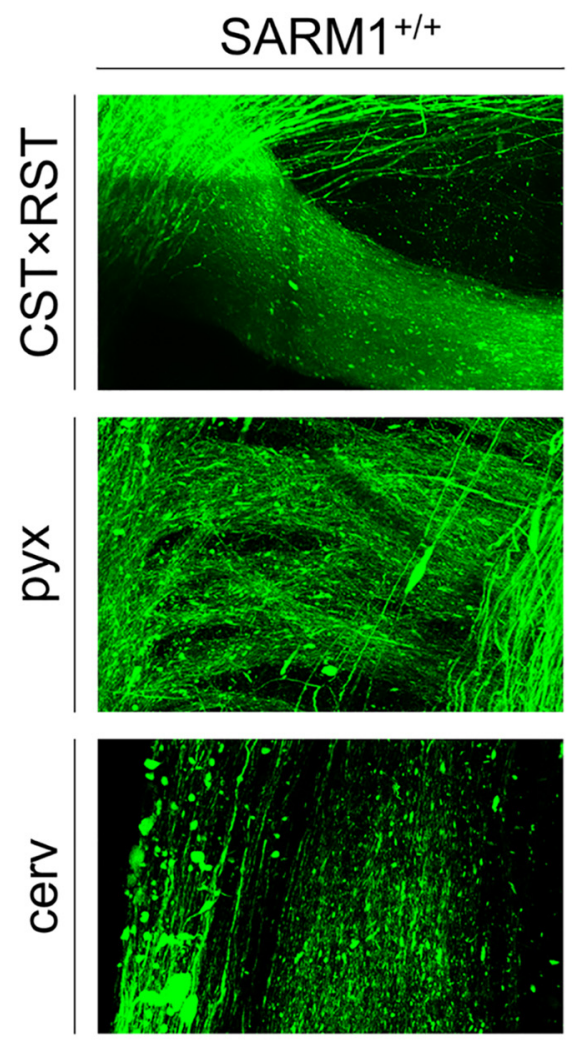

B
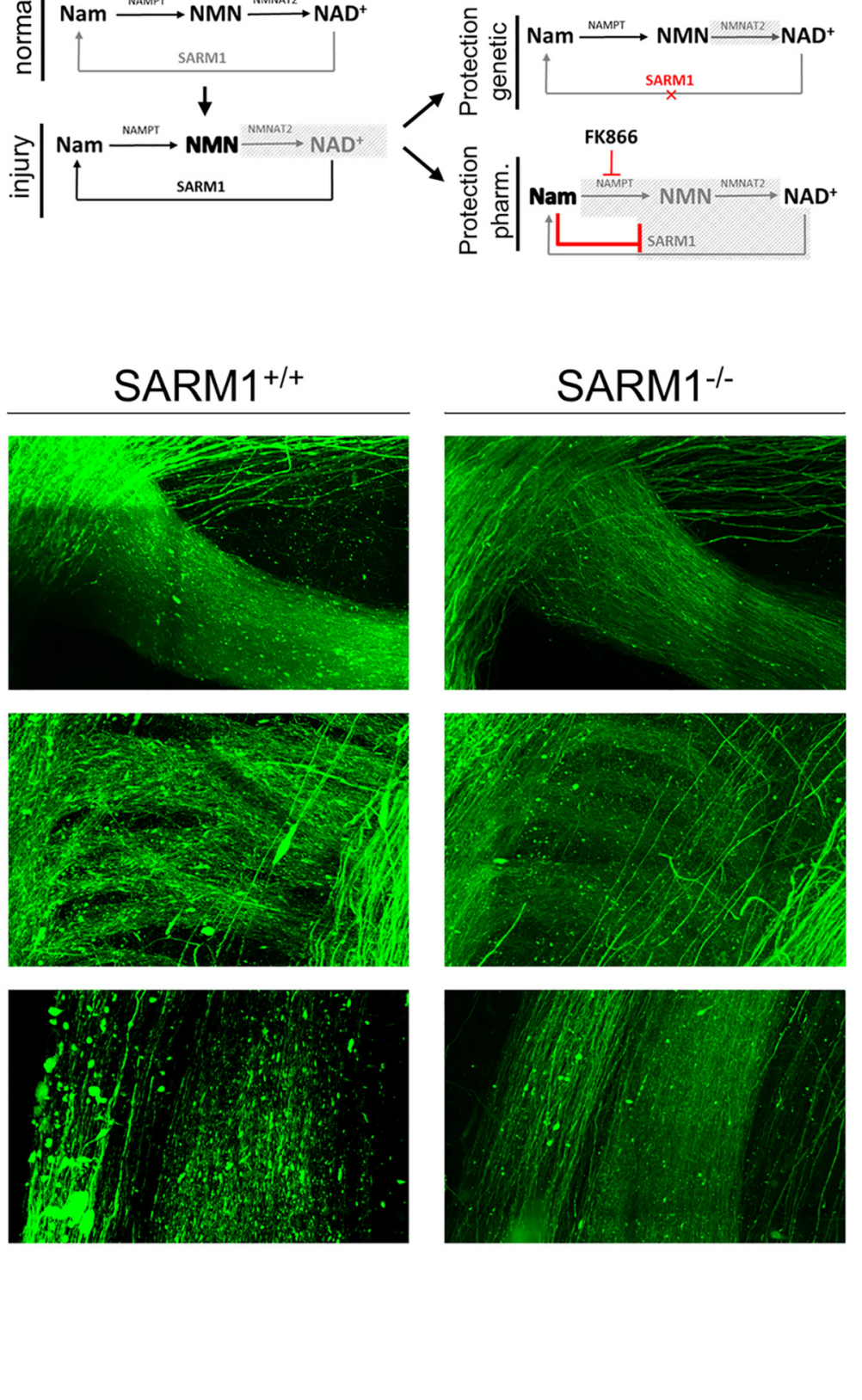

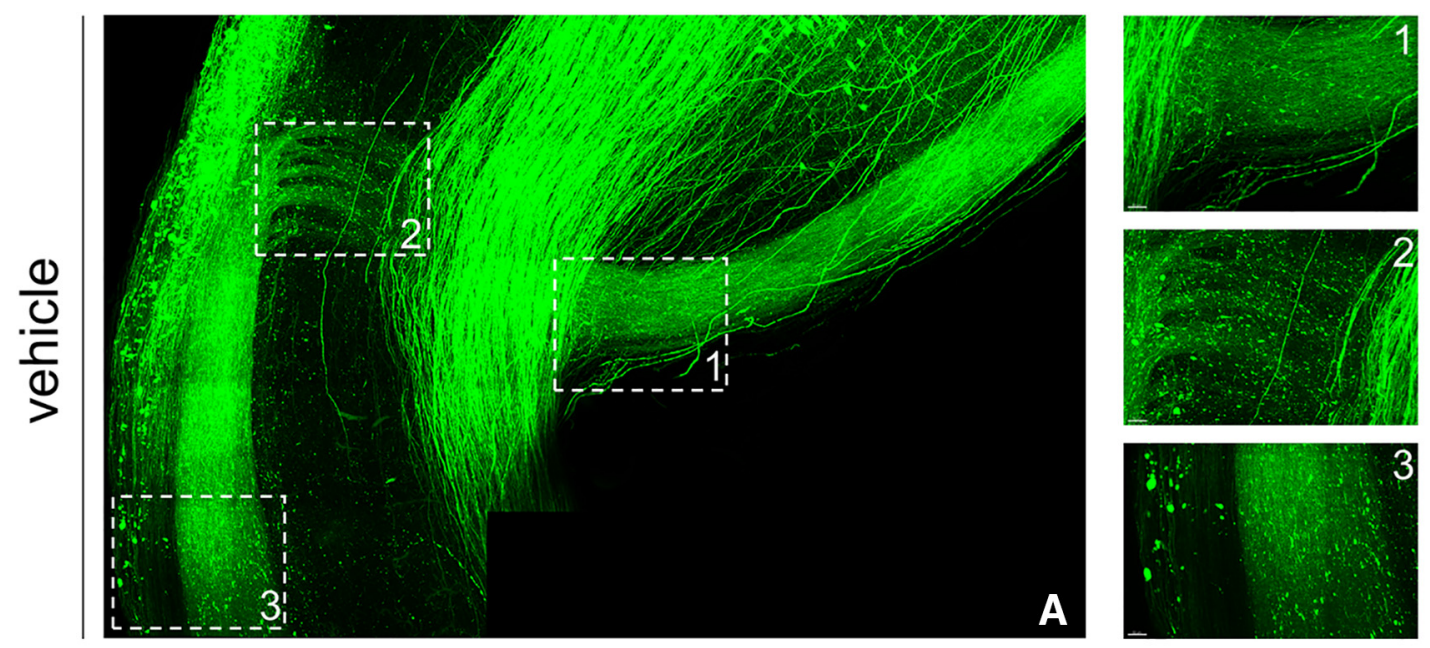

A
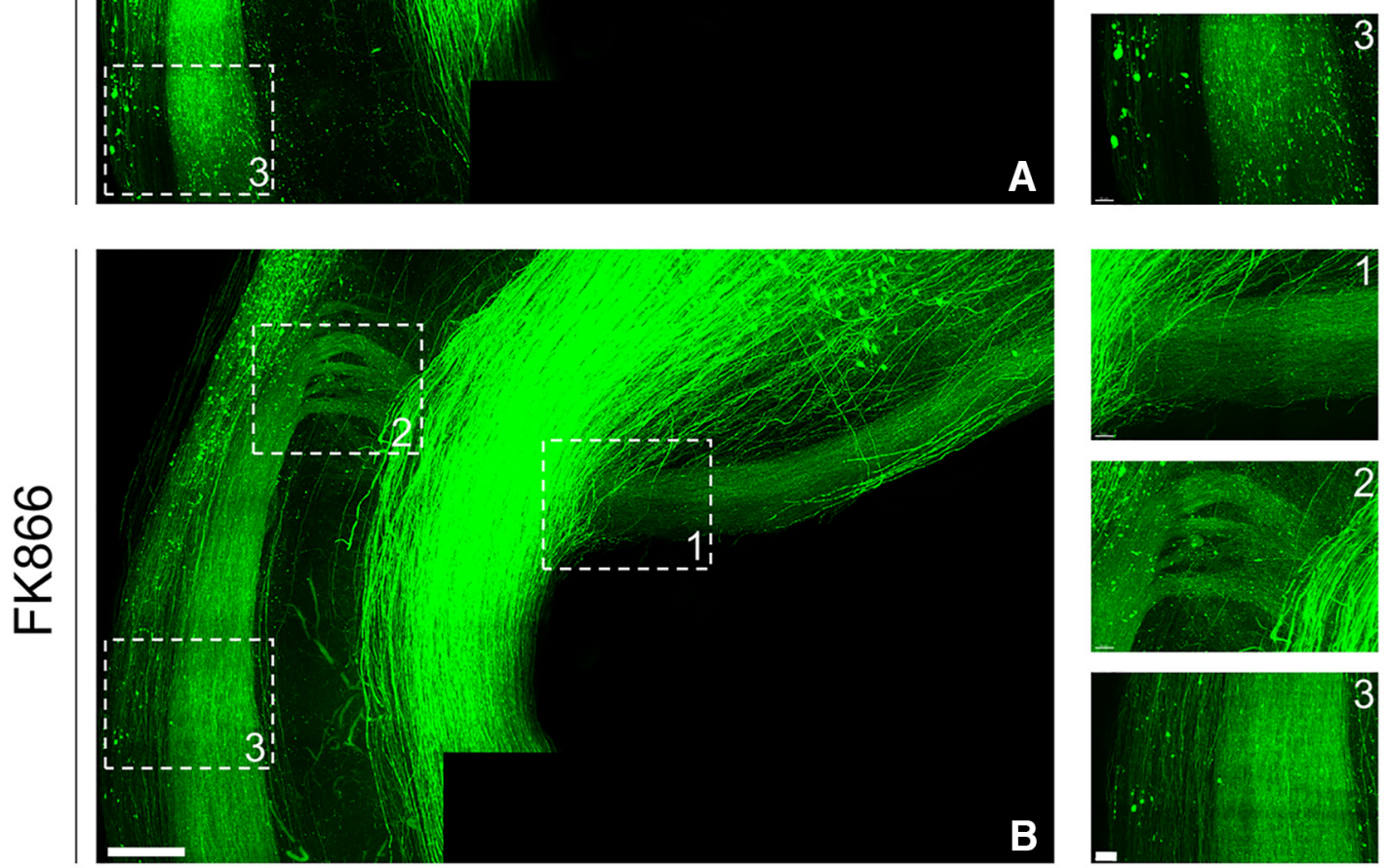

Total lesions

Density CST×RST

Density pyx
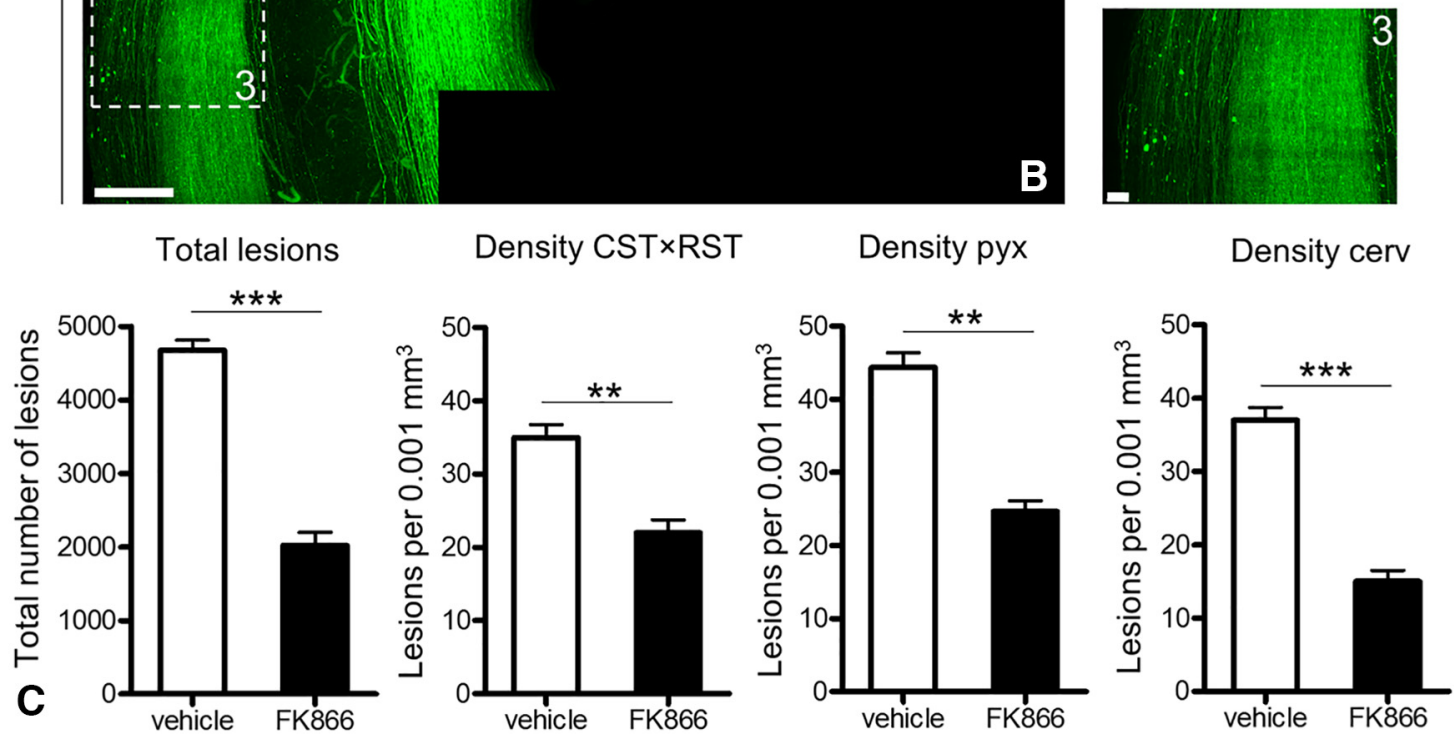

Figure 13. Protective effect of pharmacological interference with NMNAT2-SARM1 pathway at $24 \mathrm{~h}$ after injury. $\boldsymbol{A}, \boldsymbol{B}$, Sagittal images of cleared brainstems treated with vehicle $(\boldsymbol{A})$ and FK866 $(\boldsymbol{B})$, focusing on the CST and showing the concentration of axonal lesions in its medullary and upper cervical CST portions. There is a smaller number of axonal lesions in the FK866-treated brains. The CST $\times$ RST junction (1), decussation (2), and cervical spinal cord (3) of the vehicle and FK866-treated brains are further enlarged on the right. Scale bars: A, B, 300 $\mu \mathrm{m} ; \boldsymbol{A 1}-\mathbf{A 3}, \mathbf{B 1}-\mathbf{B 3}, 60 \mu \mathrm{m}$. C, Left, Counts of total number of axonal lesions in CST $24 \mathrm{~h}$ after injury. Right, Densities of lesions in three key segments (CST $\times$ RST, pyramidal decussation [pyx], and cervical cord [cerv]). Error bars indicate mean \pm SEM. Group values were analyzed with Student's $t$ test: ${ }^{* *} p<0.01$; ${ }^{* * *} p<0.001$.

axons. The advantages of CLARITY are important for the assessment of TAI, especially in long tracts with complex trajectories, in which abnormalities are not distributed uniformly over the length of the axon. Moreover, coupling of CLARITY with automated spot detection analysis allows for an accurate, unbiased, and reproducible count of the totality of axonal lesions that is an improvement over stereological methodologies. Comparisons between CLARITY-resolved APP $(+)$ and YFP $(+)$ swellings at two time points in the first day after injury shows that YFP swellings are more numerous; in addition, YFP $(+)$ swellings increase, whereas APP $(+)$ swellings decrease in number over time. In light of other studies showing the transient presence of APP immunoreactivity in injured axons (Stone et al., 2000, 2002; Greer et al., 2013; Gu et al., 2017; Yu et al., 2017), these CLARITY data show that transgenic YFP labeling may be a more sensitive and accurate way to study traumatic axonopathy, perhaps be- 
cause the long-lived YFP is more representative of axonopathy compared with the labile APP labeling. Even though current methodologies do not allow the EM study of CLARITY samples, ultrastructural analysis of injured CST axons at the same areas as the one identified with CLARITY shows that the axonopathy seen with fluorescent microscopy represents true axonal degeneration. Alterations in axoplasm, organelles, and the myelin sheath observed here are not compatible with axonal viability and are similar to the ones seen in other TBI models (Greer et al., 2011; Winston et al., 2013; Mierzwa et al., 2015) and in degenerative neuropathies (Weil, 2013).

The IA model results in distal CST axonopathy, mostly in the medulla/upper cervical cord, making it difficult to trace individual injured axons all the way back to their respective cell bodies. Thus, we used CTB retrograde tracing from ponto-medullary injection sites to label CST neurons and nuclear p-c-Jun as a surrogate marker of neuronal injury as proposed previously (Raghupathi et al., 2003; Greer et al., 2011). The preferred localization of p-c-JUN within CTB $(+)$ perikarya with abnormally small sizes shows that the perikarya of neurons whose axons were injured become atrophic. Also, the absence of TUNEL immunoreactivity in motor cortex at 3, 7, 14, and $30 \mathrm{~d}$ after injury (i.e., time points coinciding with a period of progressive atrophy) suggests that injured CST neurons do not undergo cell death, a finding consistent with the outcome of axotomy (Carter et al., 2008) or proximal axonal injury with midline fluid percussion (Greer et al., 2011). On the other hand, the persistence of CST perikarya supports the notion that traumatic axonopathy in the CST is primarily the result of axonal events triggered by trauma and not of neuronal cell death. Parallel studies of axons and cell bodies in models of injury have become essential since the discovery of the $W l d^{s}$ mice that contain an in-frame fusion protein that seems to protect axons from Wallerian degeneration but has no effect on retrograde cell death (Coleman and Freeman, 2010; Wang et al., 2015). Conversely, axonal degeneration is independent of the apoptosis-regulating proteins $\mathrm{Bcl}-2$, Bak, and Bax (Coleman, 2005). Our CLARITY protocol offers single-axon resolution in 3D and may eventually allow the tracing of individual long axons back to their cell bodies and a direct comparison between axonal and perikaryal injury.

Using CLARITY preparations, we explored the role of a key molecular mechanism of axonal degeneration (i.e., the NMNAT2SARM1 pathway) in TAI-associated axonopathy. We manipulated this pathway with genetic deletion of SARM1 and pharmacological interference via FK866 administration, and we found a significant protection in the early stages of axonopathy. These novel findings point to an important early role of the NMNAT2SARM1 pathway in traumatic axonopathy and are consistent with previous observations on a protective effect of SARM1 deletion, especially on the behavior of animals subjected to a weight-drop model of TBI (Henninger et al., 2016). The endurance of this effect needs to be ascertained with future studies using serial time points after injury and combined with studies of the downstream connections of CST. Even so, the present findings showcase the advantage of CLARITY in research on mechanisms of traumatic axonopathies and suggest that axonal degeneration can be pharmacologically manipulated, at least in the early stages.

The CST, a bundle of axons representative of CNS long tracts with a clear separation between cell bodies and axons and a complex $3 \mathrm{D}$ course, is an excellent model system for studying primary traumatic axonopathy akin to TAI and for exploring molecular pathways of axonal degeneration. High-resolution anatomical strategies combining targeted expression of fluorescent proteins and CLARITY with optimized microscopy, substantially advance the field of TBI by precisely localizing the injury, determining severity, and ushering in a next generation of models where axonal pathologies can be more precisely linked to specific cellular and molecular processes.

\section{References}

Blackstad TW, Heimer L, Mugnaini E (1981) Experimental neuroanatomy. In: Neuroanatomical tract-tracing methods (Heimer L, Robards MJ, eds), pp 1-53. New York, NY: Springer.

Bruzzone S, Fruscione F, Morando S, Ferrando T, Poggi A, Garuti A, D'Urso A, Selmo M, Benvenuto F, Cea M, Zoppoli G, Moran E, Soncini D, Ballestrero A, Sordat B, Patrone F, Mostoslavsky R, Uccelli A, Nencioni A (2009) Catastrophic $\mathrm{NAD}^{+}$depletion in activated T lymphocytes through Nampt inhibition reduces demyelination and disability in EAE. PLoS One 4:e7897. CrossRef Medline

Busso N, Karababa M, Nobile M, Rolaz A, Van Gool F, Galli M, Leo O, So A, De Smedt T (2008) Pharmacological inhibition of nicotinamide phosphoribosyltransferase/visfatin enzymatic activity identifies a new inflammatory pathway linked to NAD. PLoS One 3:e2267. CrossRef Medline

Capurso SA, Calhoun ME, Sukhov RR, Mouton PR, Price DL, Koliatsos VE (1997) Deafferentation causes apoptosis in cortical sensory neurons in the adult rat. J Neurosci 17:7372-7384. Medline

Carter LM, Starkey ML, Akrimi SF, Davies M, McMahon SB, Bradbury EJ (2008) The yellow fluorescent protein (YFP-H) mouse reveals neuroprotection as a model mechanism underlying chondroitinase $\mathrm{ABC}$-mediated repair after spinal cord injury. J Neurosci 28:14107-14120. CrossRef Medline

Chung K, Wallace J, Kim SY, Kalyanasundaram S, Andalman AS, Davidson TJ, Mirzabekov JJ, Zalocusky KA, Mattis J, Denisin AK, Pak S, Bernstein H, Ramakrishnan C, Grosenick L, Gradinaru V, Deisseroth K (2013) Structural and molecular interrogation of intact biological systems. Nature 497:332-337. CrossRef Medline

Clatterbuck RE, Price DL, Koliatsos VE (1998) Peripheral nerve grafts exert trophic and tropic effects on anterior thalamic neurons. Neurobiol Dis 5:17-26. CrossRef Medline

Coleman M (2005) Axon degeneration mechanisms: commonality amid diversity. Nat Rev Neurosci 6:889-898. CrossRef Medline

Coleman MP, Freeman MR (2010) Wallerian degeneration, WldS, and Nmnat. Annu Rev Neurosci 33:245-267. CrossRef Medline

Essuman K, Summers DW, Sasaki Y, Mao X, DiAntonio A, Milbrandt J (2017) The SARM1 Toll/Interleukin-1 receptor domain possesses intrinsic $\mathrm{NAD}^{+}$cleavage activity that promotes pathological axonal degeneration. Neuron 93:1334-1343.e5. CrossRef Medline

Farkas O, Povlishock JT (2007) Cellular and subcellular change evoked by diffuse traumatic brain injury: a complex web of change extending far beyond focal damage. Prog Brain Res 161:43-59. CrossRef Medline

Feng G, Mellor RH, Bernstein M, Keller-Peck C, Nguyen QT, Wallace M, Nerbonne JM, Lichtman JW, Sanes JR (2000) Imaging neuronal subsets in transgenic mice expressing multiple spectral variants of GFP. Neuron 28:41-51. CrossRef Medline

Finn JT, Weil M, Archer F, Siman R, Srinivasan A, Raff MC (2000) Evidence that Wallerian degeneration and localized axon degeneration induced by local neurotrophin deprivation do not involve caspases. J Neurosci 20: 1333-1341. Medline

Gerdts J, Brace EJ, Sasaki Y, DiAntonio A, Milbrandt J (2015) SARM1 activation triggers axon degeneration locally via $\mathrm{NAD}^{+}$destruction. Science 348:453-457. CrossRef Medline

Gerdts J, Summers DW, Milbrandt J, DiAntonio A (2016) Axon self-destruction: new links among SARM1, MAPKs, and NAD ${ }^{+}$metabolism. Neuron 89:449-460. CrossRef Medline

Gilley J, Coleman MP (2010) Endogenous Nmnat2 is an essential survival factor for maintenance of healthy axons. PLoS Biol 8:e1000300. CrossRef Medline

Greer JE, McGinn MJ, Povlishock JT (2011) Diffuse traumatic axonal injury in the mouse induces atrophy, c-jun activation, and axonal outgrowth in the axotomized neuronal population. J Neurosci 31:5089-5105. CrossRef Medline

Greer JE, Hånell A, McGinn MJ, Povlishock JT (2013) Mild traumatic brain injury in the mouse induces axotomy primarily within the axon initial segment. Acta Neuropathol 126:59-74. CrossRef Medline 
Gu Y, Jukkola P, Wang Q, Esparza T, Zhao Y,Brody D, Gu C (2017) Polarity of varicosity initiation in central neuron mechanosensation. J Cell Biol 216:2179-2199. CrossRef Medline

Hånell A, Greer JE, McGinn MJ, Povlishock JT (2015) Traumatic brain injury-induced axonal phenotypes react differently to treatment. Acta Neuropathol 129:317-332. CrossRef Medline

Haynes SE, Hollopeter G, Yang G, Kurpius D, Dailey ME, Gan WB, Julius D (2006) The P2Y12 receptor regulates microglial activation by extracellular nucleotides. Nat Neurosci 9:1512-1519. CrossRef Medline

Henninger N, Bouley J, Sikoglu EM, An J, Moore CM, King JA, Bowser R, Freeman MR, Brown RH Jr (2016) Attenuated traumatic axonal injury and improved functional outcome after traumatic brain injury in mice lacking Sarm1. Brain 139:1094-1105. CrossRef Medline

Hill CS, Coleman MP, Menon DK (2016) Traumatic axonal injury: mechanisms and translational opportunities. Trends Neurosci 39:311-324. CrossRef Medline

Kobayashi K, Yamanaka H, Fukuoka T, Dai Y, Obata K, Noguchi K (2008) $\mathrm{P} 2 \mathrm{Y} 12$ receptor upregulation in activated microglia is a gateway of $\mathrm{p} 38$ signaling and neuropathic pain. J Neurosci 28:2892-2902. CrossRef Medline

Kobeissy FH (2015) Brain neurotrauma: molecular, neuropsychological, and rehabilitation aspects. Boca Raton, FL: CRC.

Li J, Zhang J, Yoganandan N, Pintar F, Gennarelli T (2007) Regional brain strains and role of falx in lateral impact-induced head rotational acceleration. Biomed Sci Instrum 43:24-29. Medline

Marmarou A, Foda MA, van den Brink W, Campbell J, Kita H, Demetriadou K (1994) A new model of diffuse brain injury in rats: I. Pathophysiology and biomechanics. J Neurosurg 80:291-300. CrossRef Medline

Maxwell WL, Watt C, Graham DI, Gennarelli TA (1993) Ultrastructural evidence of axonal shearing as a result of lateral acceleration of the head in non-human primates. Acta Neuropathol 86:136-144. CrossRef Medline

Mierzwa AJ, Marion CM, Sullivan GM, McDaniel DP, Armstrong RC (2015) Components of myelin damage and repair in the progression of white matter pathology after mild traumatic brain injury. J Neuropathol Exp Neurol 74:218-232. CrossRef Medline

Nahimana A, Attinger A, Aubry D, Greaney P, Ireson C, Thougaard AV, Tjørnelund J, Dawson KM, Dupuis M, Duchosal MA (2009) The NAD biosynthesis inhibitor APO866 has potent antitumor activity against hematologic malignancies. Blood 113:3276-3286. CrossRef Medline

National Academy Press (2011) Guide for the care and use of laboratory animals, Ed 8. Washington, DC: National Academy.

Osterloh JM, Yang J, Rooney TM, Fox AN, Adalbert R, Powell EH, Sheehan AE, Avery MA, Hackett R, Logan MA, MacDonald JM, Ziegenfuss JS, Milde S, Hou YJ, Nathan C, Ding A, Brown RH Jr, Conforti L, Coleman $\mathrm{M}$, Tessier-Lavigne M, et al. (2012) dSarm/Sarm1 is required for activation of an injury-induced axon death pathway. Science 337:481-484. CrossRef Medline

Paxinos G, Franklin KB (2012) Paxinos and Franklin's the mouse brain in stereotaxic coordinates. Amsterdam, the Netherlands: Elsevier.

Porrero C, Rubio-Garrido P, Avendaño C, Clascá F (2010) Mapping of fluorescent protein-expressing neurons and axon pathways in adult and developing Thy1-eYFP-H transgenic mice. Brain Res 1345:59-72. CrossRef Medline

Raghupathi R, Muir JK, Fulp CT, Pittman RN, McIntosh TK (2003) Acute activation of mitogen-activated protein kinases following traumatic brain injury in the rat: implications for posttraumatic cell death. Exp Neurol 183:438-448. CrossRef Medline

Sasaki Y, Vohra BP, Baloh RH, Milbrandt J (2009) Transgenic mice expressing the Nmnat 1 protein manifest robust delay in axonal degeneration in vivo. J Neurosci 29:6526-6534. CrossRef Medline

Sasaki Y, Nakagawa T, Mao X, DiAntonio A, Milbrandt J (2016) (2016) NMNAT1 inhibits axon degeneration via blockade of SARM1-mediated $\mathrm{NAD}^{+}$depletion. eLife 5:e19749. CrossRef Medline

Smith DH, Chen XH, Xu BN, McIntosh TK, Gennarelli TA, Meaney DF (1997) Characterization of diffuse axonal pathology and selective hippocampal damage following inertial brain trauma in the pig. J Neuropathol Exp Neurol 56:822-834. CrossRef Medline
Smith DH, Meaney DF, Shull WH (2003) Diffuse axonal injury in head trauma. J Head Trauma Rehabil 18:307-316. CrossRef Medline

Stone JR, Singleton RH, Povlishock JT (2000) Antibodies to the C-terminus of the beta-amyloid precursor protein (APP): a site specific marker for the detection of traumatic axonal injury. Brain Res 871:288-302. CrossRef Medline

Stone JR, Okonkwo DO, Singleton RH, Mutlu LK, Helm GA, Povlishock JT (2002) Caspase-3-mediated cleavage of amyloid precursor protein and formation of amyloid beta peptide in traumatic axonal injury. J Neurotrauma 19:601-614. CrossRef Medline

Summers DW, Gibson DA, DiAntonio A, Milbrandt J (2016) SARM1specific motifs in the TIR domain enable $\mathrm{NAD}^{+}$loss and regulate injuryinduced SARM1 activation. Proc Natl Acad Sci U S A 113:E6271-E6280. CrossRef Medline

Szretter KJ, Samuel MA, Gilfillan S, Fuchs A, Colonna M, Diamond MS (2009) The immune adaptor molecule SARM modulates tumor necrosis factor alpha production and microglia activation in the brainstem and restricts West Nile virus pathogenesis. J Virol 83:9329-9338. CrossRef Medline

Tomer R, Ye L, Hsueh B, Deisseroth K (2014) Advanced CLARITY for rapid and high-resolution imaging of intact tissues. Nat Protoc 9:1682-1697. CrossRef Medline

Van Gool F, Gallí M, Gueydan C, Kruys V, Prevot PP, Bedalov A, Mostoslavsky R, Alt FW, De Smedt T, Leo O (2009) Intracellular NAD levels regulate tumor necrosis factor protein synthesis in a sirtuin-dependent manner. Nat Med 15:206-210. CrossRef Medline

Walker LJ, Summers DW, Sasaki Y, Brace EJ, Milbrandt J, DiAntonio A (2017) MAPK signaling promotes axonal degeneration by speeding the turnover of the axonal maintenance factor NMNAT2. eLife 6:e22540. CrossRef Medline

Waller A (1850) Experiments on the section of the glossopharyngeal and hypoglossal nerves of the frog, and observations of the alterations produced thereby in the structure of their primitive fibres. Philos Trans R Soc Lond 140:423-429.

Wang J, Hamm RJ, Povlishock JT (2011) Traumatic axonal injury in the optic nerve: evidence for axonal swelling, disconnection, dieback, and reorganization. J Neurotrauma 28:1185-1198. CrossRef Medline

Wang JT, Medress ZA, Vargas ME, Barres BA (2015) Local axonal protection by WldS as revealed by conditional regulation of protein stability. Proc Natl Acad Sci U S A 112:10093-10100. CrossRef Medline

Weil A (2013) Pathology of the myelin sheath and the axis-cylinder. In: Textbook of neuropathology, Ed 2 (revised and enlarged): pathology of the myelin sheath and the axis-cylinder, pp 45-62. Oxford, UK: ButterworthHeinemann.

Winston CN, Chellappa D, Wilkins T, Barton DJ, Washington PM, Loane DJ, Zapple DN, Burns MP (2013) Controlled cortical impact results in an extensive loss of dendritic spines that is not mediated by injury-induced amyloid-beta accumulation. J Neurotrauma 30:1966-1972. CrossRef Medline

Xiong Y, Mahmood A, Chopp M (2013) Animal models of traumatic brain injury. Nat Rev Neurosci 14:128-142. CrossRef Medline

Xu L, Nguyen JV, Lehar M, Menon A, Rha E, Arena J, Ryu J, MarshArmstrong N, Marmarou CR, Koliatsos VE (2016) Repetitive mild traumatic brain injury with impact acceleration in the mouse: multifocal axonopathy, neuroinflammation, and neurodegeneration in the visual system. Exp Neurol 275:436-449. CrossRef Medline

Yamada J, Jinno S (2013) Novel objective classification of reactive microglia following hypoglossal axotomy using hierarchical cluster analysis. J Comp Neurol 521:1184-1201. CrossRef Medline

Yu F, Shukla DK, Armstrong RC, Marion CM, Radomski KL, Selwyn RG, Dardzinski BJ (2017) Repetitive model of mild traumatic brain injury produces cortical abnormalities detectable by magnetic resonance diffusion imaging, histopathology, and behavior. J Neurotrauma 34:13641381. CrossRef Medline

Zhang J, Yoganandan N, Pintar FA, Gennarelli TA (2006) Role of translational and rotational accelerations on brain strain in lateral head impact. Biomed Sci Instrum 42:501-506. Medline 